Check for updates

Cite this: J. Mater. Chem. A, 2020, 8 , 16061

Received 11th October 2019 Accepted 25th November 2019

DOI: 10.1039/c9ta11221a

rsc.li/materials-a

\section{Emerging polyanionic and organic compounds for high energy density, non-aqueous potassium-ion batteries}

\author{
Mingzhe Chen, (iD *ab Qiannan Liu, (D) b Yanyan Zhang, ${ }^{\text {a }}$ Guichuan Xing, ${ }^{a}$ \\ Shu-Lei Chou (D)*b and Yuxin Tang (D) *a
}

Potassium ion batteries (PIBs) as promising energy storage candidates have attracted increasing attention due to the low-cost and abundant potassium resources. Despite numerous emerging electrode materials, the development of PIBs has consecutively encountered major challenges compared with lithium-ion batteries (LIBS) and sodium-ion batteries (SIBS), such as low reversible specific capacities, inferior cycling stabilities, and unsatisfactory energy densities. In light of this, we provide a state-of-theart review on the development of emerging classes of cathode materials, especially for polyanionic composites and organic compounds, with the aim of achieving high energy density for non-aqueous PIBs. First of all, we highlight the recent development of electrode materials towards non-aqueous PIBs with the discussion on their existing problems and the potential solutions. Then, the recent advancements in polyanionic and organic compounds towards achieving high energy density of PIBs are provided. We focus on their structure-performance relationships with a comparison of their electrochemical properties, and further promising investigations of these types of cathode materials are identified and discussed as well. Finally, personal perspectives on future optimization on cathode materials towards realizing the real applications in PIBs are constructively discussed. anstitute of Applied Physics and Materials Engineering, University of Macau, Macau, China.E-mail: yxtang@um.edu.mo

${ }^{b}$ Institute for Superconducting and Electronic Materials, Australian Institute for Innovative Materials, University of Wollongong, Innovation Campus, Squires Way, North Wollongong, NSW 2522, Australia.E-mail:mc800@uowmail.edu.au; shulei@ uow.edu.au

\section{Introduction}

In the past several decades, the rapid consumption of traditional fossil fuels has led to severe environmental challenges such as global warming. ${ }^{1}$ Renewable energy sources are environmentally friendly, as has been witnessed by their fast development in recent years. ${ }^{2}$ As a result, cost-efficient energy storage and conversion devices are strongly required because of

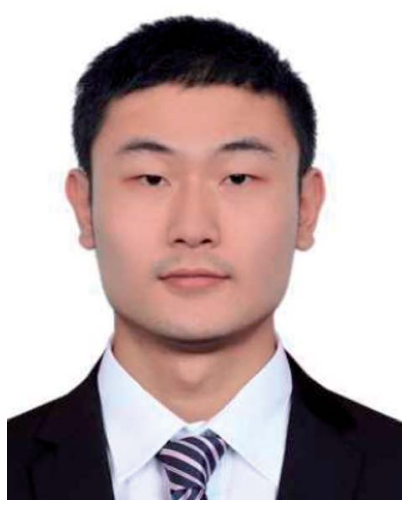

Mingzhe Chen received his Masters degree in 2015 from Sichuan University, China. He obtained his PhD degree at the Institute for Superconducting and Electronic Materials, University of Wollongong under the supervision of $\mathrm{Dr}$ Shu-Lei Chou and Prof. Shi-Xue Dou in 2019. His research is focused on advanced, low-cost electrodes for both lithium-ion batteries and sodium-ion batteries.

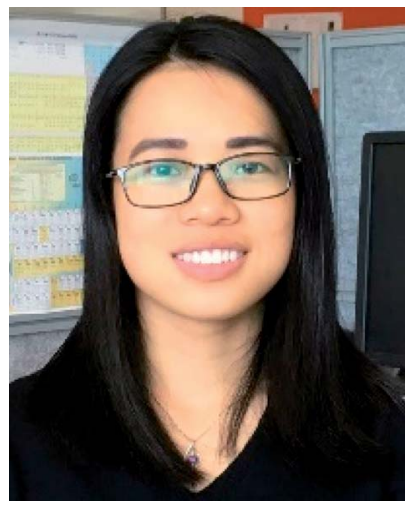

Qiannan Liu is a post-doc fellow at the Institute for Superconducting and Electronic Materials (ISEM), University of Wollongong (UOW). She received her Bachelors degree (2011) and Masters degree (2014) in materials science and engineering from Central South University, China. She obtained her PhD from ISEM, UOW in 2018. Her research focuses on the synthesis and characterization of electrode materials for sustainable energy storage and conversion applications. 
the intermittent nature of renewable energy sources. ${ }^{3}$ Lithiumion batteries (LIBs) are the most successful commercialised state-of-the-art power sources for portable electronic devices and electric vehicles (EVs). ${ }^{4,5}$ In the long run, however, fast consumption of the limited lithium resources leaves an open question as to whether or not LIBs are the most feasible energy storage media. Therefore, seeking alternative energy storage systems in a more cost-efficient way with earth-abundant elements is a preferable approach for large-scale energy storage facilities. ${ }^{6-8}$

Both sodium-ion batteries (SIBs) and potassium-ion batteries (PIBs) have attracted much research attention in recent years, since they both share similar advantages with LIBs while having significantly reduced manufacturing costs. ${ }^{9-11}$ In particular, compared to SIBs, KIBs are more attractive, since they possess some unique advantages: (i) $\mathrm{K}^{+} / \mathrm{K}$ has a low standard electrode potential in carbonate ester-based electrolytes $\left(-2.93 \mathrm{~V}\right.$ for $\mathrm{K}^{+} / \mathrm{K}$ vs. standard hydrogen electrode (SHE) and $-2.71 \mathrm{~V}$ for $\mathrm{Na}^{+} / \mathrm{Na} v s$. $\mathrm{SHE}$ ); (ii) graphite can be utilized as a suitable anode for PIBs with stable performance; (iii) in liquid electrolytes, the charge density of $\mathrm{K}^{+}$ions is lower than that of $\mathrm{Li}^{+}$and $\mathrm{Na}^{+}$ions, which only induces smaller solvated cations and is beneficial for fast ionic conductivity and high power; (iv) less expensive Al current collectors can be adapted for the production of electrodes since $\mathrm{K}$ metal will not alloy with $\mathrm{Al}$. These merits make PIBs strong competitors to SIBs and even LIBs. ${ }^{12-15}$

The development of high-performance cathode materials still remains a major challenge for the practical application of PIBs. Suitable cathode candidates should store more $\mathrm{K}^{+}$ions with high capacity, high working potential, fast $\mathrm{K}^{+}$ion transport, and long cycle life, leading to the high energy density of PIBs. ${ }^{16}$ Since the radius of $\mathrm{K}^{+}$is much larger than those of $\mathrm{Na}^{+}$ and $\mathrm{Li}^{+}$, the crystal structures of hosts for $\mathrm{K}^{+}$ions are more vulnerable to extended cycling, ${ }^{\mathbf{1 7}}$ and the corresponding potential $\mathrm{K}^{+}$ion hosts possess different working voltages and potassium storage mechanisms from those of their LIB and SIB counterparts. At present, some types of electrodes have already been investigated as potential cathode materials, such us layered transition-metal oxides, ${ }^{\mathbf{1 8 , 1 9}}$ Prussian blue analogues (PBAs), ${ }^{20,21}$ polyanionic composites, ${ }^{22}$ and organic compounds. ${ }^{23}$ Although layered transition-metal oxides have been very successful in commercial LIBs, most K-containing oxides, such as P2-type and P3-type $\mathrm{K}_{x} \mathrm{CoO}_{2}$ and $\mathrm{K}_{x} \mathrm{MnO}_{2}$, suffer from low working potential and complex phase transitions with unstable crystal structures during cycling, ${ }^{24-26}$ while for PBAs, they show relatively high working platforms in $\mathrm{K}$ half-cells, and their threedimensional (3D) structures would greatly favour fast $\mathrm{K}^{+}$ion insertion/extraction. Indeed, PBAs feature small volume change during charge/discharge, although their air stability remains a troublesome issue for real application. ${ }^{27}$ Similar to PBAs, various types of polyanionic compounds also possess robust 3D open framework structures, endowing fast ionic diffusion. ${ }^{14}$ In addition, they are usually air-stable, and most of the reported polyanionic compounds have fixed high working potentials with satisfactory cycling stabilities, both of which are critical parameters for reliable energy storage systems. Organic compounds are also considered to be attractive candidates due to their low manufacturing costs and flexible, tunable structures. ${ }^{28}$ They usually possess relatively good cycling stabilities and high achievable specific capacities, which deserve wider and more in-depth investigations. Among these cathode material candidates, it is necessary to pay special attention to polyanionic and organic compounds since their high voltage platforms as well as high specific capacities are the key routes to achieve high energy density for PIBs.

In this review, we first review the state-of-the-art development of electrode materials (anodes and cathodes) towards non-aqueous potassium storage materials. In recent years, a large volume of various types of potassium hosts with multiple structures have been intensively investigated for both cathode and anode materials. Considering the natural abundance of potassium, many encouraging potassium analogues of PIB electrodes have been used with promising electrochemical

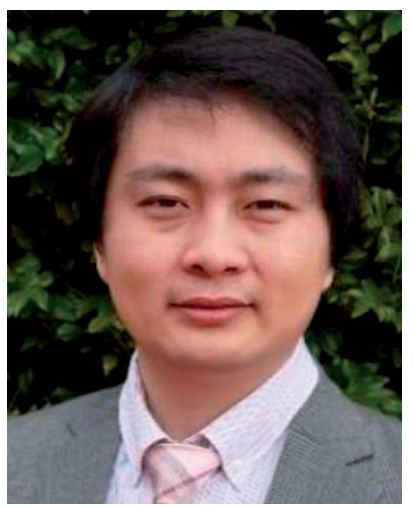

Shu-Lei Chou is currently an associate professor at the Institute for Superconducting and Electronic Materials, University of Wollongong. He received his PhD degree from the University of Wollongong in 2010. His research interests include energy storage materials for battery applications, especially novel composite materials, new binders, and new electrolytes for $\mathrm{Li} / \mathrm{Na}$ batteries.

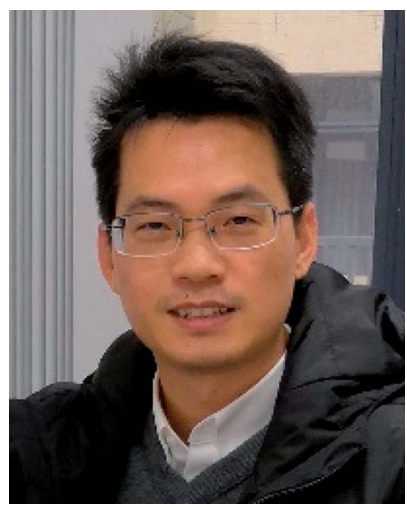

Dr Tang Yuxin is an Assistant Professor in the Institute of Applied Physics and Materials Engineering (IAPME) at University of Macau. He obtained his B.S. and M.S. degrees at the Nanjing University of Aeronautics and Astronautics in 2006 and 2009, respectively, and graduated from Nanyang Technological University (NTU, Singapore) with a PhD in Materials science (2013). After his postdoctoral fellow training at NTU, he joined IAPME as Assistant Professor in 2018. His research interests include solid-state and fast charging energy storage devices, and the development of realtime electrochemical reaction monitoring techniques. 
properties, as shown in Fig. 1. Then, we systematically summarize the recent progress in the development of polyanionic and organic compounds for non-aqueous PIBs, anticipating future guidance and directions to solve the major disadvantages of polyanionic and organic candidates. Special attention will be given to the key factors such as long-term cycling stability and working potential for practical application concern in the future. Finally, personal perspectives are provided with fruitful strategies for their future optimization towards realizing the real applications of cathode materials in PIBs.

\section{Overview of the current electrolyte materials for potassium-ion batteries}

\subsection{Cathode materials}

Inspired by the rocking-chair alkali ion working mechanisms, finding potential potassium hosts with rigid structures and high voltage windows to accommodate continuous $\mathrm{K}^{+}$ion de-l insertion is very important. Considering the large ion size and heavier molecular weight of the $\mathrm{K}^{+}$ion, a series of great challenges are inevitably encountered with previous recognised structures for LIBs and SIBs, such as inferior reversible capacities and large volume changes, which remain the key obstacles for the high performance of PIBs. Therefore, we initially overview the current states of cathode materials and make comparisons to obtain an in-depth understanding.

Layered metal oxides for PIBs are the primary targets of researchers since they have received tremendous success in LIBs and SIBs. Although they usually suffer from large volume changes and structural deformation during cycling, they can

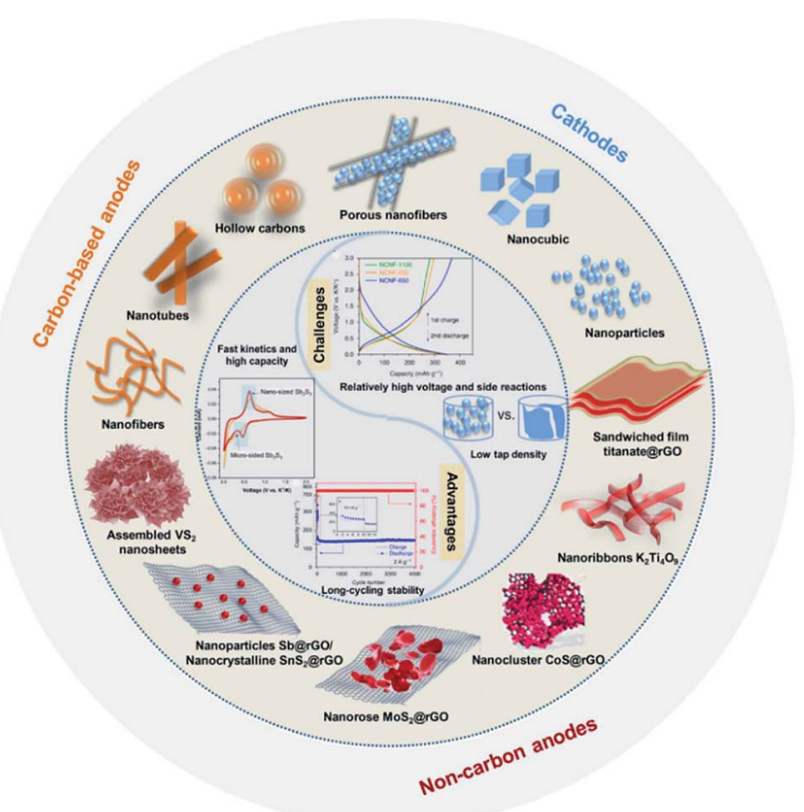

Fig. 1 Schematic illustration of the different structured electrodes for PIBs and corresponding advantages and challenges. Reproduced with permission. ${ }^{29}$ Copyright 2019, AAAS not only utilize a variety of redox couples with expected reversible capacities, but also sustain fixed voltage platforms with relatively stable structures. The layered oxides can be traditionally classified with an alpha-numeric expression defined by Delmas and colleagues. ${ }^{30}$ The alkali site coordination is identified, such as $\mathrm{O}$ for octahedral and $\mathrm{P}$ for prismatic, and a number represents the oxygen stacking sequence. This structure initially provides a two-dimensional (2D) framework for the rapid transportation of alkali ions, even for the large radius of $\mathrm{K}^{+}$ions. The mechanism for potassium to be stabilized depends on two key primary characteristics: the compatibility of their interstitial sites where available and the possible coordination environment of potassium ions within specific electronic configurations. This mechanism is also restricted by the degree of electrostatic repulsion between the intercalated cations and the local oxygen atoms.

$\mathrm{K}_{x} \mathrm{CoO}_{2}$ and $\mathrm{K}_{x} \mathrm{MnO}_{2}$ were introduced as suitable cathodes for PIBs in recent years. $\mathrm{K}_{0.3} \mathrm{MnO}_{2}$, with a distorted P2-type structure in orthorhombic symmetry (space group $\mathrm{Cmcm}$ ), was reported by Vaalma et al. in 2016. ${ }^{31}$ This material can be recharged in the voltage window of $1.5-4.0 \mathrm{~V}$ with a reversible capacity of $125 \mathrm{~mA} \mathrm{~h} \mathrm{~g}^{-1}$. A P3-type $\mathrm{K}_{0.5} \mathrm{MnO}_{2}$ (Fig. 2a and b) was also demonstrated to exhibit a capacity of $110 \mathrm{~mA} \mathrm{~h} \mathrm{~g}^{-1}$ between 1.5 and $3.9 \mathrm{~V} .^{18}$ Both materials can reach higher capacities at elevated cut-off voltage, where there has always been fast capacity fading (Fig. 2c and d). Also, a non-potassium-deficient O3-type $\mathrm{KCrO}_{2}$ reported by Kim et al., as shown in Fig. 2e and f, has shown remarkable progress, since it is the only layered oxide that can host $\mathrm{K}^{+}$ions without potassium deficiency. ${ }^{32}$ Nevertheless, its average working platform is relatively low $(\sim 2.7 \mathrm{~V})$ with a reversible capacity of $93 \mathrm{~mA} \mathrm{~h} \mathrm{~g}{ }^{-1}$. The participation of the $\mathrm{Cr}^{3+} / \mathrm{Cr}^{4+}$ redox couple can minimize the negative effects of $\mathrm{K}^{+}-\mathrm{K}^{+}$interactions, which usually destabilize the layered structure (as shown in Fig. $2 \mathrm{~g}$ ).

Other researchers found that partial replacement of $\mathrm{Mn}^{3+}$ by $\mathrm{Fe}^{3+}$ can effectively suppress the strong Jahn-Teller effect of $\mathrm{Mn}^{3+}$ due to the elevated valence of $\mathrm{Mn}^{33}$ In addition, the multiple phase transformation can be smoothed, which still remains a major drawback of layered K-oxides. For example, a modified $\mathrm{P} 2-\mathrm{Na}_{2 / 3}\left[\mathrm{Fe}_{1 / 2} \mathrm{Mn}_{1 / 2}\right] \mathrm{O}_{2}$ cathode could reach a high specific capacity of $190 \mathrm{~mA} \mathrm{~h} \mathrm{~g}^{-1}$ and retain $150 \mathrm{~mA} \mathrm{~h} \mathrm{~g}{ }^{-1}$ after 30 cycles. $^{33} \mathrm{~A} \mathrm{~K}_{0.7} \mathrm{Fe}_{0.5} \mathrm{Mn}_{0.5} \mathrm{O}_{2} /$ soft carbon full PIB cell was fabricated by Mai et al., and high capacity retention of $76 \%$ was available after 250 cycles (Fig. $2 \mathrm{~h}$ and i). ${ }^{34}$ Its unique stable framework and nanowire morphology both contributed fast kinetics and facile charge transportation. Nevertheless, the upper cut-off voltage still remains a big challenge for all types of K-containing layered oxides, since the deeper discharge states will result in severe structural instability. This phenomenon is still not clear, and it deserves to be investigated in-depth to further utilize potential reversible capacity.

Prussian blue analogues (PBAs) are well-known as a large group of metal-organic frameworks. They possess outstanding merits such as cheap transition metal components, long cycle life, and facile large-scale production. They usually crystallize in cubic symmetry with open $3 \mathrm{D}$ frameworks, which can sustain large alkali ions such as $\mathrm{Na}^{+}$and $\mathrm{K}^{+}$to de-/insert without 

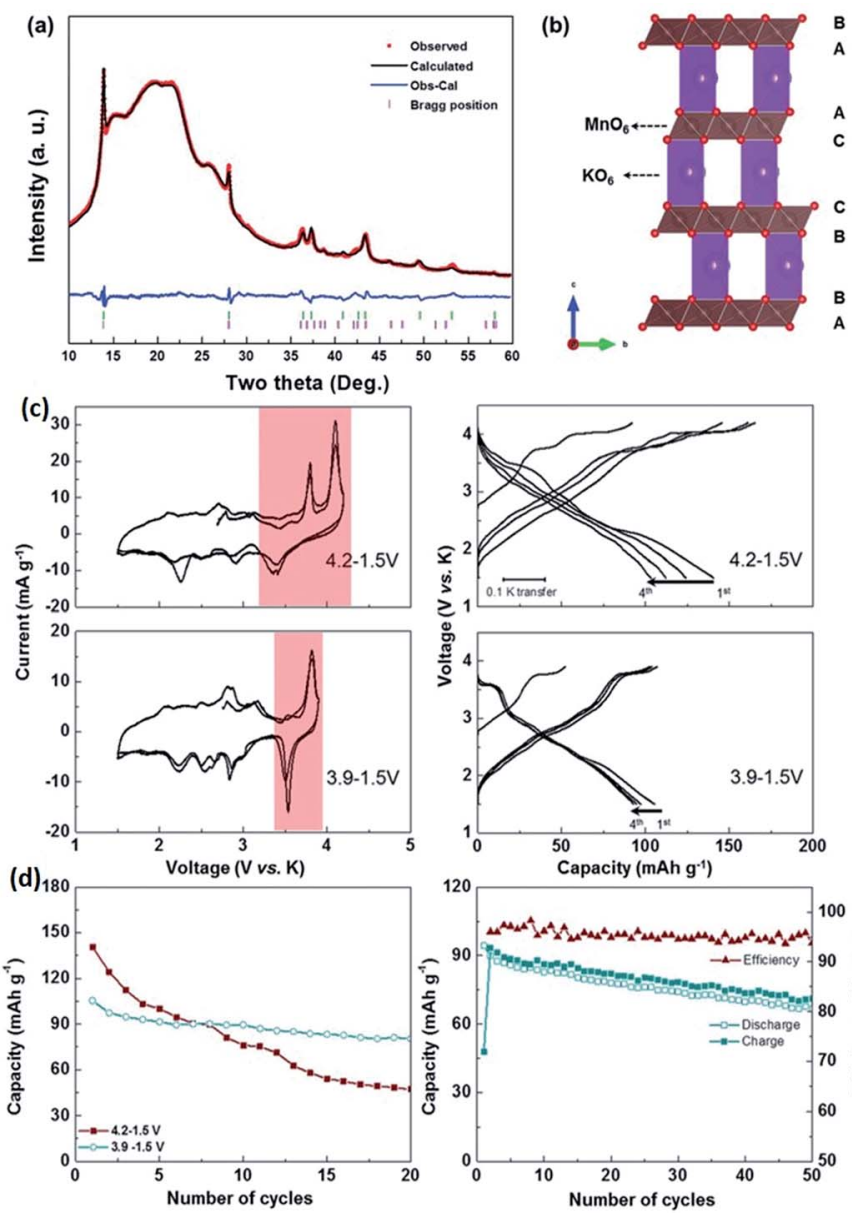
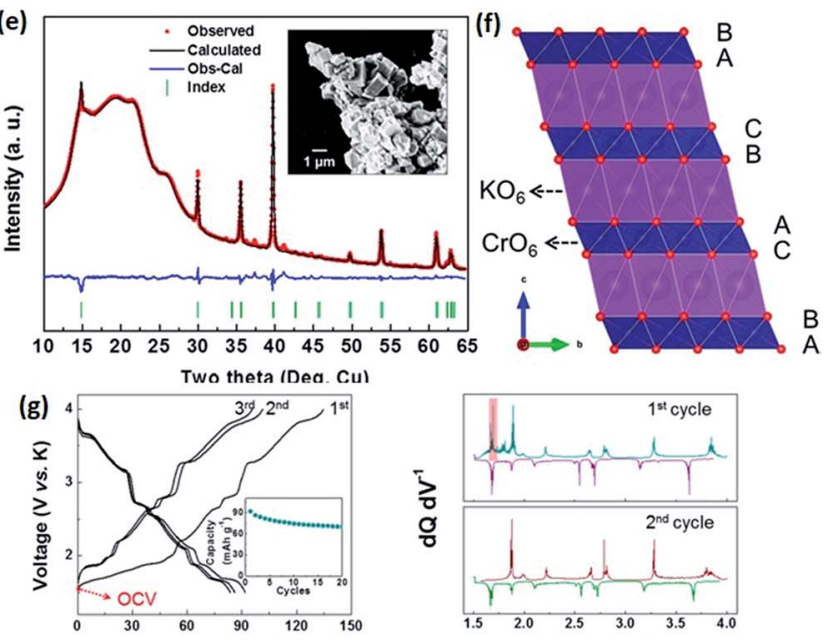

Capacity (mAh g $\left.{ }^{-1}\right)$
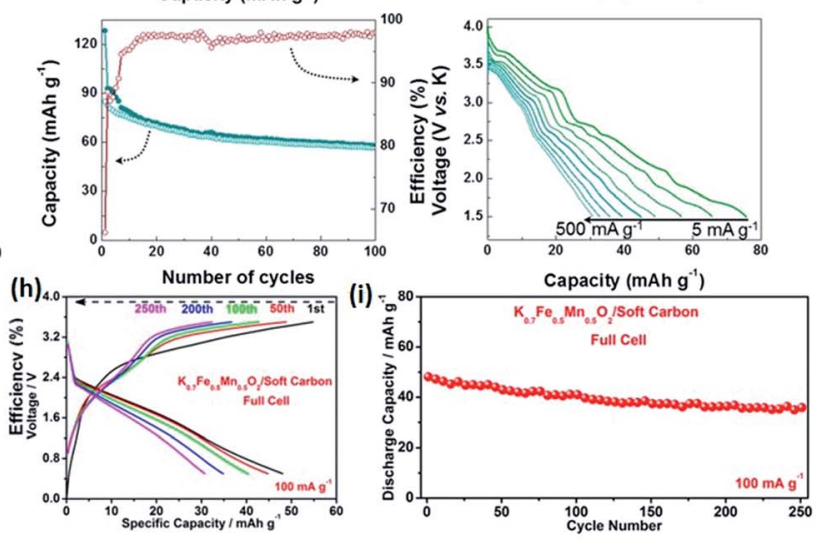

Fig. 2 (a) Rietveld refinement results for the as-obtained $\mathrm{K}_{0.5} \mathrm{MnO}_{2}$ material. An $R 3 \mathrm{~m}$ major phase and a Cmcm minor phase were fitted together to yield the weighted profile reliability factor, $R_{\mathrm{wp}}=3.2 \%$. (b) Schematic illustration of the P3-type $\mathrm{K}_{0.5} \mathrm{MnO}_{2}$ structure. (c) Cyclic voltammograms and corresponding charge/discharge profiles of the P3-type $\mathrm{K}_{0.5} \mathrm{MnO}_{2}$ material in different voltage windows. (d) Cycling stability in different voltage windows of the P3-type $\mathrm{K}_{0.5} \mathrm{MnO}_{2}$ structure. Reproduced with permission. ${ }^{18}$ Copyright 2017, Wiley-VCH. (e) Rietveld refinement results and scanning electron microscope (SEM) image (inset) for the as-prepared $\mathrm{O} 3-\mathrm{KCrO}_{2}$. (f) Schematic illustration of the $\mathrm{O} 3-\mathrm{KCrO}_{2}$ structure. (g) Electrochemical properties in different cycles and at different current densities. Reproduced with permission. ${ }^{32}$ Copyright 2018 , American Chemical Society. ( $h$ and i) Full cell performance based on $\mathrm{K}_{0.7} \mathrm{Fe}_{0.5} \mathrm{Mn}_{0.5} \mathrm{O}_{2} /$ soft carbon. Reproduced with permission. ${ }^{34}$ Copyright 2016 American Chemical Society.

structural instability. ${ }^{35}$ Their general composition can be expressed as $\mathrm{K}_{x} \mathrm{M}_{\mathrm{A}}\left[\mathrm{M}_{\mathrm{B}}(\mathrm{CN})_{6}\right]_{1-\delta} \cdot \mathrm{nH}_{2} \mathrm{O}$, where $\mathrm{M}_{\mathrm{A}}$ and $\mathrm{M}_{\mathrm{B}}$ stand for the $\mathrm{N}$-coordinated and C-coordinated transition metals, and $\delta$ represents the contents of $\left[\mathrm{M}_{\mathrm{B}}(\mathrm{CN})_{6}\right]$ vacancies and water residuals. ${ }^{21}$ Two main features of these PBA materials are highly appreciated for SIBs and PIBs. (i) There are sufficient large 3D channels for sodium/potassium ion diffusion and relatively low diffusion energy barriers. (ii) The contents of $\left[\mathrm{MB}(\mathrm{CN})_{6}\right]$ vacancies and water residuals can be reduced by a specially designed synthesis process, which is critical for high reversible capacity and long-term cycling stability.

Although K-PBAs show slightly lower specific capacities than that of Na-PBAs due to the heavier $\mathrm{K}^{+}$ions, their higher voltage platforms lead to competitive high energy densities. Zhu et al. recently employed $\mathrm{K}_{0.61} \mathrm{Fe}\left[\mathrm{Fe}(\mathrm{CN})_{6}\right]_{0.91} \cdot 0.32 \mathrm{H}_{2} \mathrm{O}$ and $\mathrm{K}_{0.22} \mathrm{Fe}$ $\left[\mathrm{Fe}(\mathrm{CN})_{6}\right]_{0.85} \cdot 0.64 \mathrm{H}_{2} \mathrm{O}$ as cathode materials to fabricate highenergy-density flexible PIBs (Fig. 3a-e). The Prussian blue (PB) electrodes produced by photographic printing showed good cycling stabilities and excellent rate capabilities (Fig. $3 \mathrm{f}$ and g). ${ }^{20}$ Zhang et al. reported a comprehensive study on $\mathrm{K}_{0.22} \mathrm{Fe}$ $\left[\mathrm{Fe}(\mathrm{CN})_{6}\right]_{0.805} \cdot 4.01 \mathrm{H}_{2} \mathrm{O}$ nanoparticles, and they found that the carbon-coordinated $\mathrm{Fe}^{2+} / \mathrm{Fe}^{3+}$ redox couple was highly active and mainly responsible for the overall structural stability during cycling, while the corresponding excellent rate capability can also be attributed to this reason (Fig. $3 \mathrm{~h}$ and i).$^{36} \mathrm{High}$-quality $\mathrm{FeFe}(\mathrm{CN})_{6}$ was also synthesized by Shadike et al. with good electrochemical performances. ${ }^{37}$ Chong et al. investigated $\mathrm{KFe}^{\mathrm{II}}\left[\mathrm{Fe}^{\mathrm{III}}(\mathrm{CN})_{6}\right]$ material with various ex situ characterizations, and its excellent electrochemical properties are attributed to its robust structural stability. ${ }^{38}$

Nazar's group recently reported a Prussian white analogue, $\mathrm{K}_{1.7} \mathrm{Fe}\left[\mathrm{Fe}(\mathrm{CN})_{6}\right]_{0.9}$, with suitable crystallite sizes. They found that the particle size plays an important role in its ultimate electrochemical performance. ${ }^{39}$ Nevertheless, K-PBAs are sensitive to synthetic procedures, air exposure, water content, and particle size, and how these key parameters influence their 

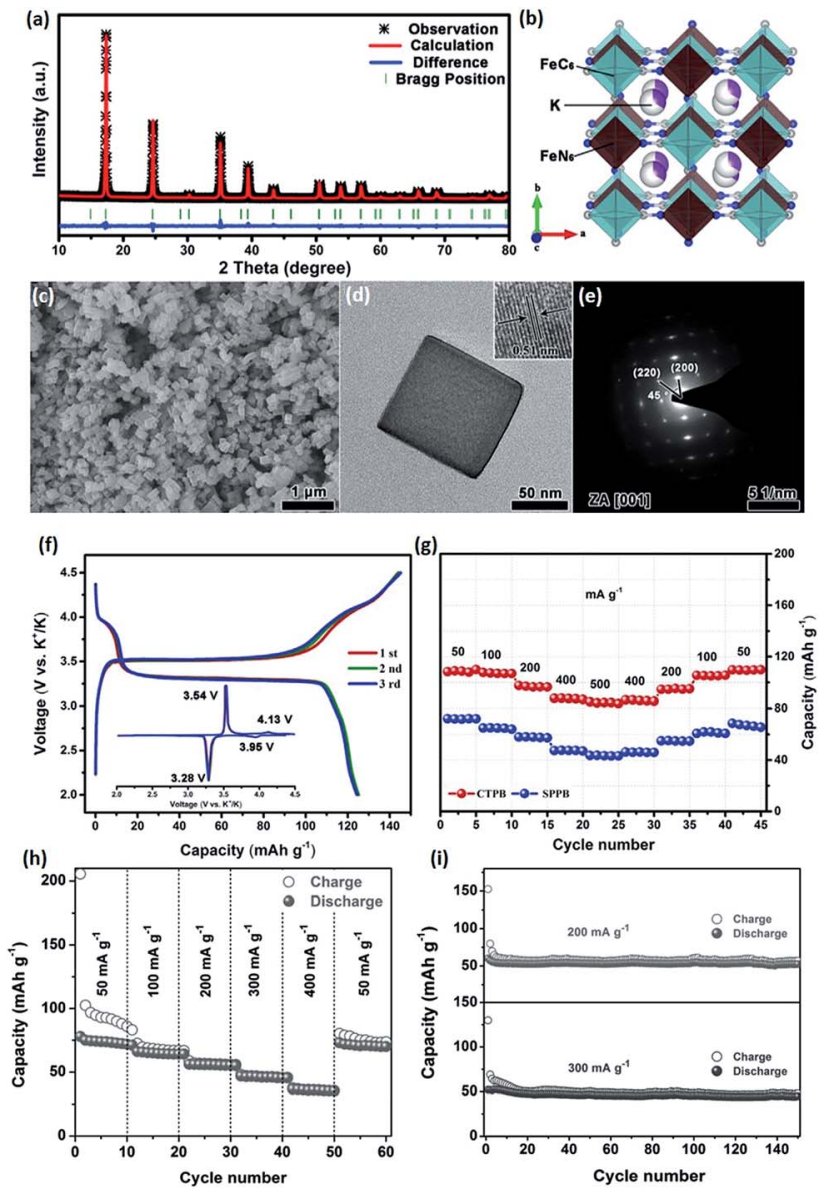

Fig. 3 (a) Rietveld refinement results for as-prepared PB nanocubes. (b) Corresponding schematic illustration. (c) SEM, and (d) transmission electron microscope (TEM) images of as-obtained PB nanocubes. (e) Selected area electron diffraction (SAED) pattern of as-obtained PB nanocubes. ( $f$ and $g$ ) Charge/discharge curves and rate performance of as-obtained PB nanoparticles. Reproduced with permission. ${ }^{20}$ Copyright 2018 Elsevier Inc. (h) Rate and (i) cycling performances of asprepared KPBNPs/K half-cell at various current densities. Reproduced with permission. ${ }^{36}$ Copyright 2017, Wiley-VCH.

structure and crystallinity, as well as their electrochemical properties, needs to be systematically investigated. Also, more advanced techniques with in-depth characterization are urgently needed as well.

\subsection{Anode materials}

In the case of LIBs, graphite has achieved tremendous success in the commercial market, since lithium can be reversibly intercalated via forming graphite intercalation compounds (GICs) with the final product $\mathrm{LiC}_{6} \cdot{ }^{40}$ This process shows a high theoretical capacity of $372 \mathrm{~mA} \mathrm{~h} \mathrm{~g}^{-1}$ with excellent cycling stability. However, the application of graphite encountered totally different situations in SIBs and PIBs. Sodium can hardly intercalate into graphite, while GICs can be generated during the potassium intercalation, resulting in a theoretical value of $279 \mathrm{~mA} \mathrm{~h} \mathbf{g}^{-\mathbf{1}} .^{\mathbf{4 1}}$ Other carbon-based materials such as soft carbon have also been proved to have the capability to alloy with potassium ions. ${ }^{42,43}$
The mechanism of intercalation of $\mathrm{K}$ into graphite is still not completely understood. Compared to Li ions, the large-sized $\mathrm{K}$ ions require more associated carbon atoms to accommodate them. Jian et al. reported the initial electrochemical potassium insertion process in graphite in 2015 (Fig. 4a). ${ }^{41}$ Through ex situ $\mathrm{X}$-ray diffraction (XRD), they found that $\mathrm{KC}_{36}, \mathrm{KC}_{24}$, and $\mathrm{KC}_{8}$ are sequentially generated during potassiation, as shown in Fig. $4 \mathrm{~b}$ and c. Graphite exhibits moderate rate capability and fast capacity fading at high $C$-rates. Almost at the same time, Luo et al. also made similar discoveries, and decent electrochemical performances were demonstrated (Fig. 4d-g). ${ }^{43}$ They first performed ab initio calculations, and found that $\mathrm{K}$ ions also can be intercalated into reduced graphene oxide (RGO) film with higher capacity ( $222 \mathrm{~mA} \mathrm{~h}^{-1}$ ).

Similar to SIBs, large volume expansion still remains a big challenge for graphite-based materials for PIBs. The volume expansion of $\mathrm{KC}_{8}$ is around $61 \%$, while $\mathrm{LiC}_{6}$ only undergoes a $10 \%$ volume expansion. Therefore, researchers have put great efforts into ameliorating this phenomenon. For example, Ding et al. fabricated sulfur-grafted hollow carbon spheres to accommodate potassium ions for PIBs. ${ }^{44}$ The specially designed structure could provide a shortened diffusion distance $(\sim 40$ $\mathrm{nm}$ ) and strong $\mathrm{C}-\mathrm{S}$ bonds to minimize the decay of cycling capacity. He et al. incorporated nitrogen species with phosphorus doping into 3D porous carbon, and this unique structure could provide sufficient pore defects and edges, resulting in rapid interfacial $\mathrm{K}^{+}$ion absorption reactions. The fabrication process is shown in Fig. $4 \mathrm{~h} .{ }^{45}$ Ultrahigh reversible capacity and excellent $C$-rates were obtained (Fig. 4i). Nitrogen doping of fewlayered graphene was also useful for improving the reversible capacity from $278 \mathrm{~mA} \mathrm{~h} \mathrm{~g}{ }^{-1}$ to $350 \mathrm{~mA} \mathrm{~h} \mathrm{~g}{ }^{-1}$. Share et al. highlighted the importance of nitrogen dopant sites apart from $\mathrm{sp}^{3}$ carbon defects. ${ }^{46}$ In situ Raman spectroscopy demonstrated that there was a slightly different staging sequence for doped and undoped materials. Other researchers also have demonstrated various carbonaceous materials to be potential competitive candidates for PIBs. ${ }^{42,47-49}$

Recently, graphitizable carbon has aroused great interest among researchers, since their potassium storage capability is outstanding. Soft carbon is a typical example of graphitizable carbon. The degree of graphitization of soft carbon can be easily controlled by using different sintering temperatures (normally above $2000{ }^{\circ} \mathrm{C}$ ). Some natural resources and raw materials, such as pyrolytic petroleum coke, polypyrrole, and pitch, can be turned into soft carbon after high temperature calcination in a controllable process. ${ }^{50-52}$ Their potentials for sodium/ potassium ion storage, especially with surface defects, have been explored by various techniques. ${ }^{53}$

By introducing dopant atoms or surface defects, the soft carbon materials can be endowed with great potential for PIBs. For example, Ju et al. investigated few-layer F-doped graphene foam via direct synthesis processes. This material could deliver $165.9 \mathrm{~mA} \mathrm{~h} \mathrm{~g}^{-1}$ at $500 \mathrm{~mA} \mathrm{~g}^{-1}$ for 200 cycles. $^{53}$ Its high surface area and unique mesoporous membrane structures can offer sufficient active sites to accommodate large potassium ions. $\mathrm{N}$ doping and O-doping also have been demonstrated as useful strategies for improving the electrochemical properties of PIBs. 

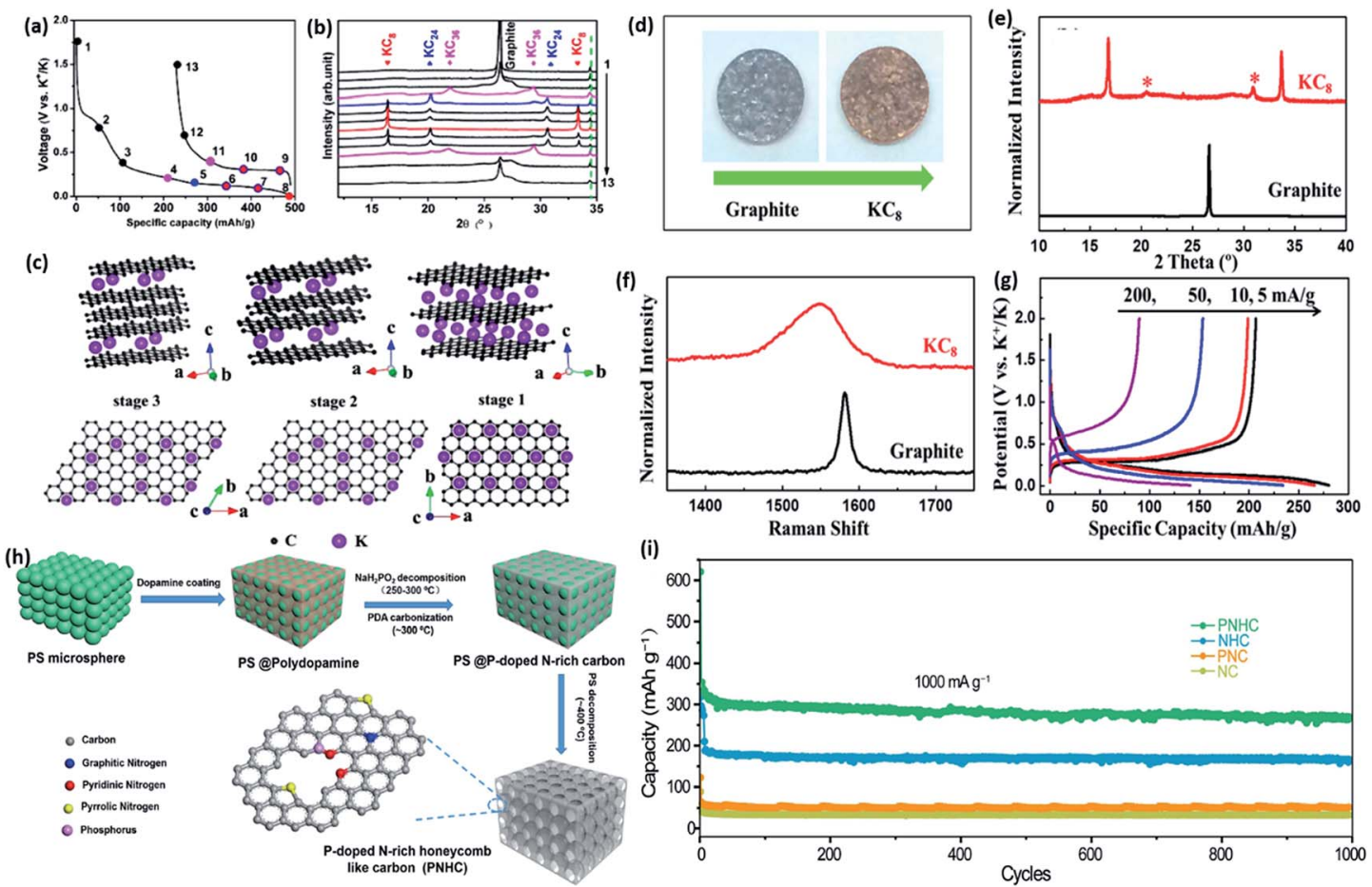

Fig. 4 (a) Initial cycle of graphite anode and (b) corresponding ex situ XRD patterns. (c) Schematic illustrations of different K-GICs with side view and top view. Reproduced with permission. ${ }^{41}$ Copyright 2015 American Chemical Society. Ex situ measurements of $\mathrm{KC}_{8}$ and graphite electrodes: (d) photographs, (e) XRD patterns, (f) Raman spectra, and (g) electrochemical profiles of graphite electrodes at different $C$-rates. Reproduced with permission. ${ }^{43}$ Copyright 2015 American Chemical Society. (h) Schematic illustration of the fabrication process for as-prepared P-doped N-rich honeycomb-like carbon. (i) Cycling performances of all prepared samples at $1000 \mathrm{~mA} \mathrm{~g}^{-1}$. Reproduced with permission. ${ }^{45}$ Copyright 2019 Elsevier, Ltd.

A polyacrylonitrile (PAN) precursor was used as the starting material with an electrospinning method. ${ }^{54}$ Dual-heteroatom doping, in theory, could offer synergistic effects on soft carbons. Phosphorus and oxygen dual-doped graphene was considered as a superior anode material for PIBs. High reversible capacity of $474 \mathrm{~mA} \mathrm{~h} \mathrm{~g}^{-1}$ was achieved at $50 \mathrm{~mA} \mathrm{~g}^{-1}$ after 50 cycles..$^{55}$ Cage-like graphitic carbon structures can also effectively reduce anisotropy and ameliorate the large volume expansion during $\mathrm{K}^{+}$intercalation/deintercalation. Their 3D electrically conducting network also promotes fast electron/ion transport. Other researchers also successfully fabricated various types of carbonaceous materials, such as pre-oxidated microstructures from pitch, nitrogen/sulfur co-doped hollow carbon nanofibers, ${ }^{51}$ and short-range ordered mesoporous carbon, and superior electrochemical properties were obtained. Further work should explore better ways to increase their initial cycle coulombic efficiency towards their real applications in full PIBs.

Apart from the graphite-based or carbon-based materials, other kinds of materials based on the intercalation reaction mechanism have also been reported recently, such as $\mathrm{K}_{2} \mathrm{Ti}_{8} \mathrm{O}_{17}{ }^{56}$ This material shows good rate performance with a micro-flower morphology. What's more, another interesting type of material for PIB anodes comprises alloy-based compounds, including $\mathrm{Si}, \mathrm{Sb}, \mathrm{Sn}, \mathrm{Mo}$, etc. ${ }^{77,58}$ These types of materials usually have higher theoretical capacities, since these elements can easily alloy with $\mathrm{K}$ atoms at various states of charges. Alloy-based materials are promising candidates for LIBs and have received intensive investigations. Since many different alloying compounds will be generated during cycling, however, huge volume expansion is inevitable. Therefore, multiple carbon matrix structures are being created to accommodate the volume shrinkage and improve the electronic/ionic conductivities. Sultana et al. first reported an Sn-based anode in PIBs with a reversible capacity of $150 \mathrm{~mA} \mathrm{~h} \mathrm{~g}^{-1}$. Zhang et al. found that concentrated electrolytes could stabilize the $\mathrm{Bi}$ based anode composites in PIBs. The Bi nanoparticles were uniformly coated with a thick carbon layer (Fig. 5a-d). They discovered that a $5 \mathrm{M}$ ether-based electrolyte could sufficiently activate the Bi-C surface. Several GICs $\left(\mathrm{K}_{5} \mathrm{Bi}_{4}, \mathrm{~K}_{3} \mathrm{Bi}, \mathrm{KBi}_{2}, \mathrm{~K}_{3} \mathrm{Bi}_{2}\right.$, $\mathrm{K}_{3} \mathrm{Bi}$ ) were found in different states of charge via ex situ XRD, as shown in Fig. 5e and f. ${ }^{59}$ Phosphorus-based alloys are also important players in high performance PIB anodes. Zhang et al. recently investigated an $\mathrm{Sn}_{4} \mathrm{P}_{3} / \mathrm{C}$ electrode obtained by a ball milling method as a safe anode material. ${ }^{60}$ They proposed that the final discharge product is possibly a nonstoichiometric $\mathrm{K}_{3-x} \mathrm{P}$ compound (Fig. 5g). Comparable electrochemical properties are displayed in Fig. 5h. Some of the $\mathrm{MoS}_{2}, \mathrm{MoSe}_{2}$ and $\mathrm{TiS}_{2}$ materials also showed promising potassium storage capabilities. Other decent carbon structures have been introduced by other researchers. ${ }^{61-64}$ Further goals for these kinds of materials should be focused on prolonging their cycling 

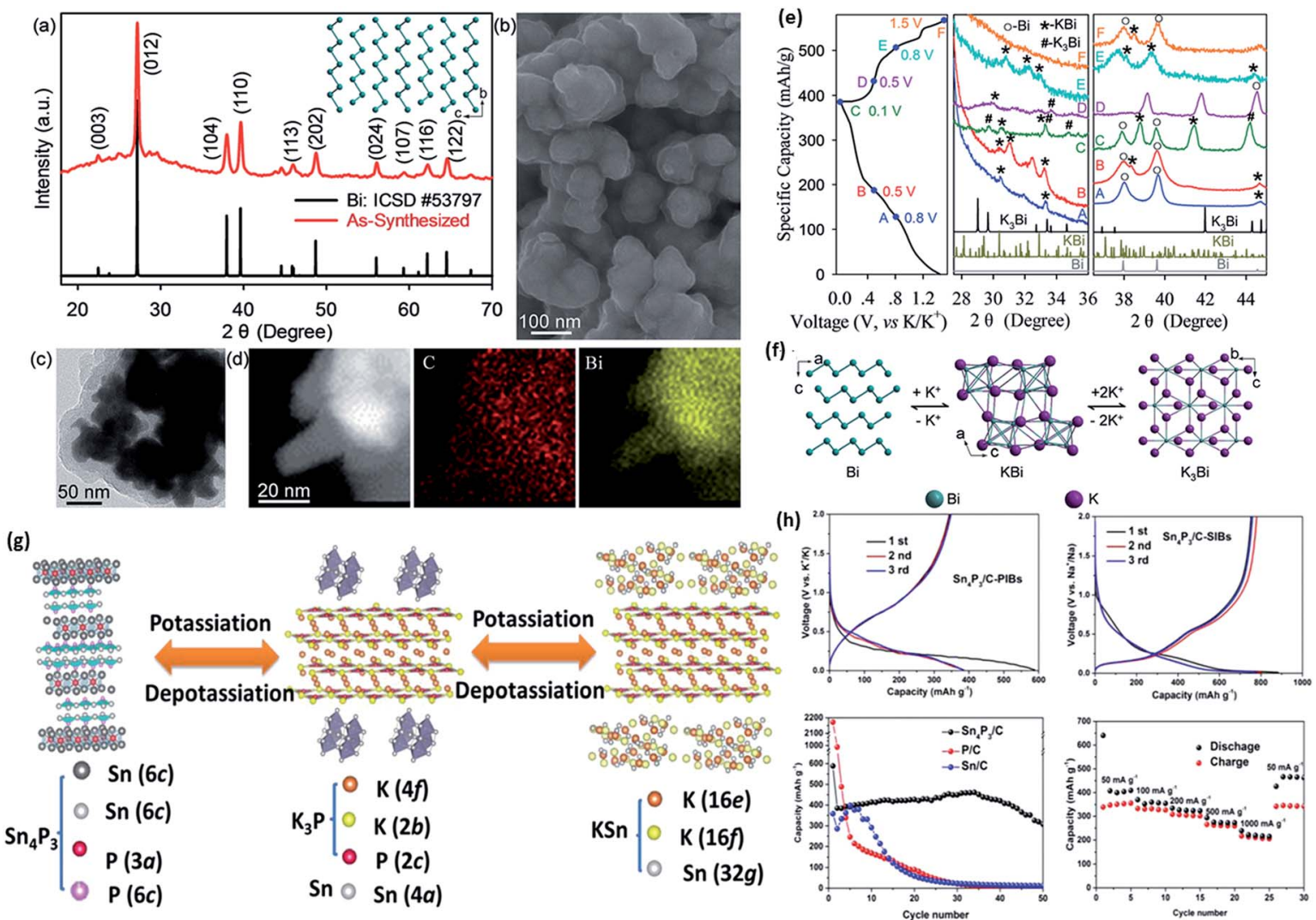

Fig. 5 (a) XRD pattern with structure in the inset and (b) SEM image of the as-obtained Bi@C nanocomposite. (c and d) TEM images and energy dispersive spectroscopy (EDS) mapping results for the Bi@C nanocomposite. (e) Ex situ XRD study of the Bi@C anode in $5 \mathrm{M}$ potassium bis(trifluoromethanesulfonyl) imide-diglyme (KTFSI-DEGDME) electrolyte. (f) Schematic illustrations of the different alloying compounds that appear during cycling. Reproduced with permission. ${ }^{59}$ Copyright 2018, Royal Society of Chemistry. (g) Schematic illustration of the potassiation/ depotassiation process in the as-fabricated $\mathrm{Sn}_{4} \mathrm{P}_{3} / \mathrm{C}$ anode. (h) Corresponding electrochemical properties of $\mathrm{P} / \mathrm{C}, \mathrm{Sn} / \mathrm{C}$, and $\mathrm{Sn}{ }_{4} \mathrm{P} / \mathrm{C}$ materials. Reproduced with permission. ${ }^{60}$ Copyright 2017, American Chemical Society.

stabilities and achieving higher initial cycle coulombic efficiencies.

\section{Why polyanionic and organic compounds are important for developing potassium storage hosts}

Potassium-ion batteries are the most important candidates for emerging energy storage systems due to the limited resources and skyrocketing price of lithium in recent years. Currently, nearly $40 \%$ of the total costs can be assigned to the active cathode and anode materials. Stable electrochemical performances of cathode materials are especially important since they are the key factors accounting for the overall energy density and cycling stability. To date, only a few types of cathodes have been reported compared to the anodes, and most of these K-cathodes only possess low energy content in terms of both volumetric energy and gravimetric energy compared to the Li-cathodes and Na-cathodes, as shown in Fig. 6a. Therefore, urgent tasks have been proposed to enable researchers to focus on the discovery of new types of cathodes and the exploration of potential improvements to existing cathodes. Since the large ionic radius of $\mathrm{K}^{+}$will result in strong $\mathrm{K}^{+}-\mathrm{K}^{+}$interactions, 3D arrangements and special $\mathrm{K}^{+}$ion hosting mechanisms should first be taken into consideration. As shown in Fig. 6b, most K-containing layered structured oxides possess low voltage platforms, and their 2D arrangements cannot properly accommodate the strong $\mathrm{K}^{+}-\mathrm{K}^{+}$interactions, which may lead to severe capacity degradation during cycling. Prussian blue analogues are promising because they have flatter voltage profiles and high
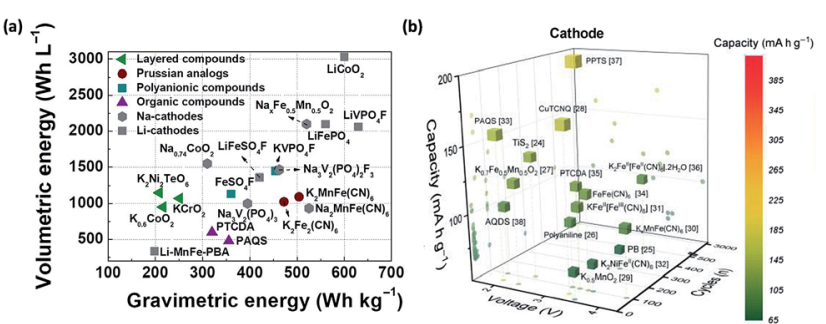

Fig. 6 (a) Gravimetric and volumetric energy densities of existing cathodes for PIBs. Reproduced with permission. ${ }^{14}$ Copyright 2019 Elsevier Inc. (b) Capacity vs. cycle number and working potentials of reported cathodes for PIBs. Reproduced with permission. ${ }^{29}$ Copyright 2019, Science Publishing Group. 
gravimetric energy, although their interstitial water residuals are hard to control, and the mechanisms influencing this remain unclear. In addition, their relatively low volumetric energy density is also a troublesome issue for their further application. Therefore, polyanionic-based and organic compounds are promising candidates to effectively increase the energy density of K-cathodes to compete with Li-cathodes and Na-cathodes with extended cycle life, due to their high working voltage and large specific capacities.

\section{Polyanionic materials as advanced potassium hosts}

Polyanionic compounds have been intensively investigated as promising cathode materials since the invention of LIBs. ${ }^{65-68}$ Various types of robust polyanionic structures, such as phosphates, fluorophosphates, pyrophosphates, sulfates, etc., have been explored as alkali ion hosts with specific electrochemical curves. The most representative atomic structures are composed of combinations of tetrahedral $\mathrm{XO}_{4}$ groups $(\mathrm{X}=\mathrm{P}, \mathrm{S}$, $\mathrm{Si}$, etc.) with corner-sharing $\mathrm{MO}_{6}$ octahedra $(\mathrm{M}=$ transition metal elements), and due to their diversified covalent framework, relatively low energy barriers to alkali metal ion migration will ensure satisfactory rate capabilities, while the strong inductive effect generated by adjacent anion groups will offer elevated working potentials as well as reinforced energy densities. Compared to other types of cathode materials, we are delighted to find that recent progress in polyanionic-based materials is showing great promises in PIBs.

\subsection{Amorphous-FePO 4}

In the last decades, olivine $\mathrm{LiFePO}_{4}$ has been well studied for LIBs and received great success in the commercial LIB market. Its thermodynamically favoured $\mathrm{Na}$ counterpart, maricite $\mathrm{NaFePO}_{4}$, lacks possible $\mathrm{Na}^{+}$ion diffusion pathways. Therefore, it is regarded to be electrochemically inactive. The feasibility of $\mathrm{K}^{+}$ion intercalation into olivine and maricite $\mathrm{A}_{1-x} \mathrm{FePO}_{4}(\mathrm{~A}=\mathrm{K})$ is almost non-existent because of the large size of the $\mathrm{K}$ ion. The amorphous forms, such as amorphous $\mathrm{FePO}_{4}$, with short range ordering were firstly investigated as potential potassium hosts for PIBs in 2014 by Mathew et al. ${ }^{69}$ They simply synthesized a dehydrated amorphous $\mathrm{FePO}_{4}$ material by a precipitationvacuum-drying method. A reversible capacity of $160 \mathrm{~mA} \mathrm{~h} \mathrm{~g}$ was achieved with a relatively low operating voltage around 2.5 V (Fig. 7a). Ex situ XRD revealed that the short-range ordering was improved after $\mathrm{K}$ ion intercalation due to a monoclinic $\mathrm{KFe}_{2}\left(\mathrm{PO}_{4}\right)_{2}$ product, and this phenomenon was reversible, since $\mathrm{KFe}_{2}\left(\mathrm{PO}_{4}\right)_{2}$ could be identified again in the second cycle. A schematic illustration of the proposed amorphous-to-crystalline transformation mechanism is shown in Fig. $7 \mathrm{~b}$, although the intrinsic amorphous nature of such materials will result in inferior cycling stability and a low working voltage platform, which may hinder their real applications in high energy PIBs in the future.

\subsection{Potassium containing phosphates/oxyphosphates}

Similar to the situation in SIBs, phosphate-based cathode materials have continued to attract increasing attention for PIBs due to the feasibility of $\mathrm{K}$ ion intercalation. A variety of redox couples of different elements are electrochemically active for both SIBs and PIBs. Similar to the well-studied sodium superionic conductor (NASICON)-type $\mathrm{Na}_{3} \mathrm{~V}_{2}\left(\mathrm{PO}_{4}\right)_{3},{ }^{70,71} \quad \mathrm{~K}_{3} \mathrm{~V}_{2}\left(\mathrm{PO}_{4}\right)_{3}$ with a 3D conductive network was first introduced by Han et al. in $2017 .{ }^{72}$ A reversible specific capacity of $55 \mathrm{~mA} \mathrm{~h} \mathrm{~g}^{-1}$ could be reached at the current density of $20 \mathrm{~mA} \mathrm{~g}^{-1}$. They specially designed a 3D porous nanostructure with a uniformly covered carbon matrix (as shown in Fig. 7c). It showed good cycling stability up to 100 cycles. Later on, Wang et al. successfully synthesized bundled $\mathrm{K}_{3} \mathrm{~V}_{2}\left(\mathrm{PO}_{4}\right)_{3}$ nanowires with ultrahigh cycling stability even after 2000 cycles, ${ }^{73}$ although its XRD pattern cannot be indexed to any existing JCPDS database based on selected phases. Zhang et al. attempted to analyse its phase constitutions, and they found that its powder diffraction can be assigned to the $R \overline{3} c$ space group with a defined NASICON structure. The Rietveld refinement of the powder diffraction pattern is displayed in Fig. $7 \mathrm{~d}^{74}$ They also constructed a symmetric full PIB, since $\mathrm{K}_{3} \mathrm{~V}_{2}\left(\mathrm{PO}_{4}\right)_{3}$ has two distinct voltage platforms, between 3.5 and $4.0 \mathrm{~V}$ and between 1.0 and $2.2 \mathrm{~V}$. Han et al. also studied a nanocubic $\mathrm{KTi}_{2}\left(\mathrm{PO}_{4}\right)_{3}$ electrode for PIBs for the first time. ${ }^{75}$ This material has a flat voltage platform of $\sim 1.6 \mathrm{~V}$, which also can be used as an anode material as well since its ICE is nearly $100 \%$, which is important for the anode part. In addition, the utilization of the second $\mathrm{K}$ ion in the $\mathrm{K}_{3} \mathrm{~V}_{2}\left(\mathrm{PO}_{4}\right)_{3}$ material is worth further exploration due to the low operation voltage. It can be used as an anode for full cells of KIBs as well. Further investigations should first completely determine the phase constitution and site occupation of each atom, and this will be significantly helpful to rationally optimise this new polyanionic compound towards higher reversible capacity and energy density. In addition, it is worth noting that a non-potassium containing material, $\mathrm{VOPO}_{4}$, has been explored as a potential cathode for PIBs. Peng et al. synthesized $2 \mathrm{D} \mathrm{VOPO}_{4}$ nanosheets with remarkable electrochemical performances. ${ }^{76}$ Hyoung et al. also introduced $\mathrm{VOPO}_{4} \cdot 2 \mathrm{H}_{2} \mathrm{O}$ as a cathode material for PIBs. ${ }^{77}$ They explored the reaction mechanism and the role of additive water in structural stabilization, and it is also suitable for wet electrolytes.

Potassium-containing oxyphosphates have also been intensively investigated in the last three years. Chihara et al. firstly reported $\mathrm{KVOPO}_{4}$ material as the cathode for PIBs in 2017. A reversible capacity of $84 \mathrm{~mA} \mathrm{~h} \mathrm{~g}^{-1}$ could be obtained in the voltage window of 2.0-5.0 V using $1 \mathrm{M} \mathrm{KPF}_{6}$ ethylene carbonate/ polypropylene carbonate (EC/PC) as the electrolyte (Fig. 7e). ${ }^{78}$ The XRD powder pattern was indexed to the Pna2 1 space group with high purity. In situ XRD revealed that the whole charging process can be assigned to a two-phase reaction. This material possesses a high voltage platform around $4.2 \mathrm{~V}$, which is important for achieving PIBs with high energy density. Lian et al. performed density functional theory (DFT) calculations to further determine the phase transformation, ionic diffusion, and charge transfer mechanism of this promising $\mathrm{KVOPO}_{4}$ 

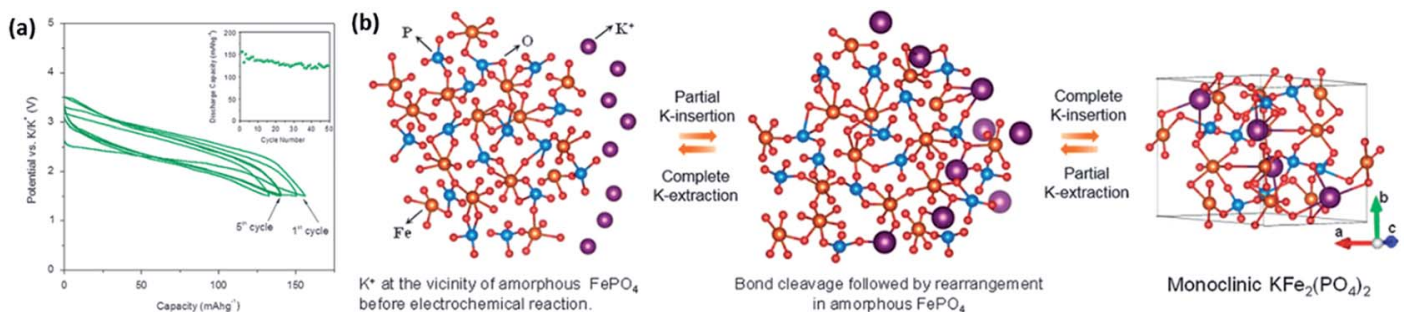

(c)
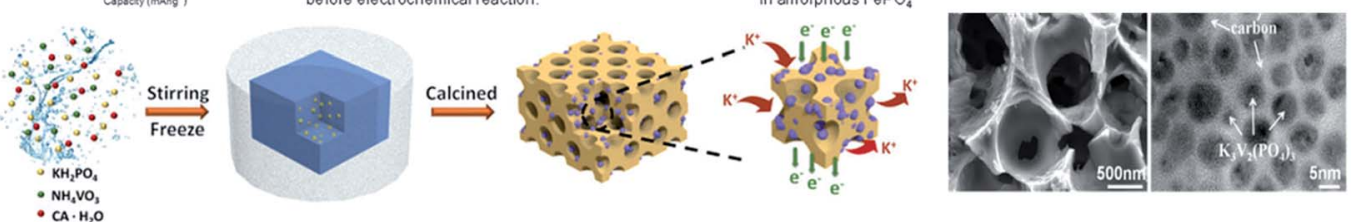

(d)
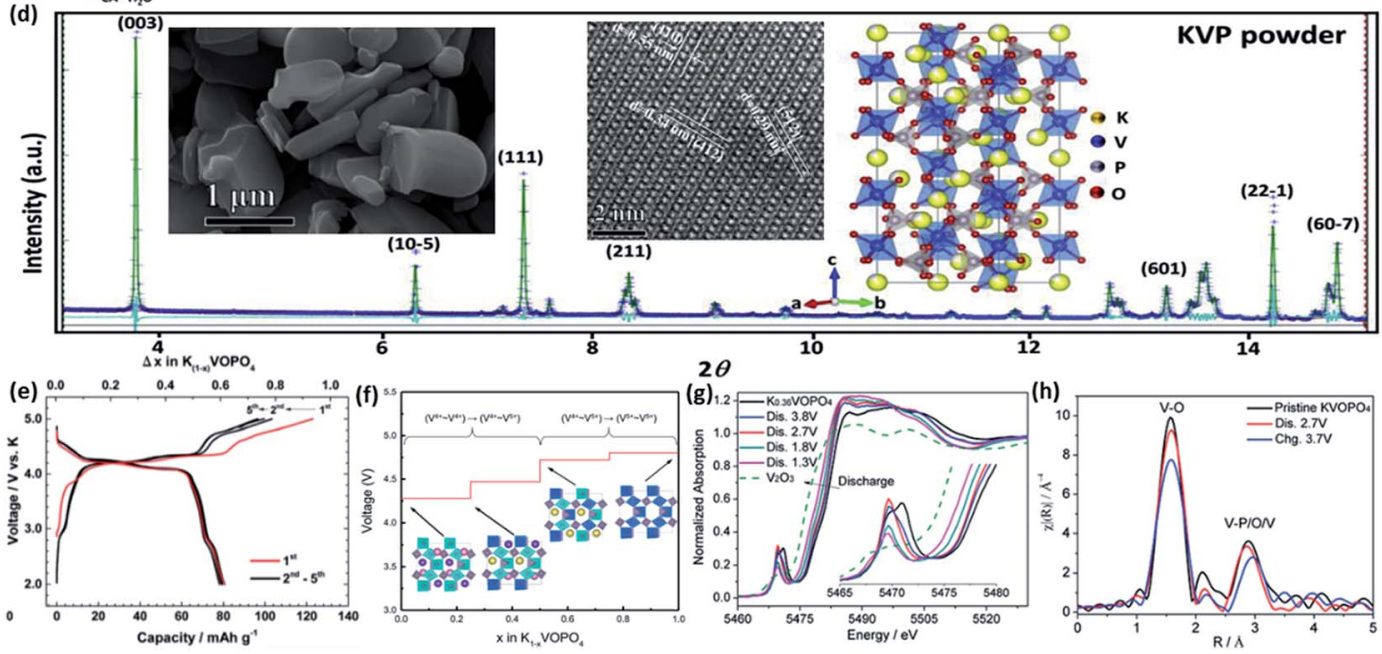

Fig. 7 (a) The initial five voltage profiles of amorphous $\mathrm{FePO}_{4}$ material. (b) Schematic illustration of the proposed amorphous-to-crystalline transformation of amorphous $\mathrm{FePO}_{4}$ hosting potassium ions. Reproduced with permission. ${ }^{69}$ Copyright 2014 Nature Publishing Group. (c) Schematic representation of the synthesis process for the 3D porous $\mathrm{K}_{3} \mathrm{~V}_{2}\left(\mathrm{PO}_{4}\right)_{3} / \mathrm{C}$ nanoparticles, and their SEM and TEM images. Reproduced with permission. ${ }^{72}$ Copyright 2017, Royal Society of Chemistry. (d) Rietveld refinement of the powder diffraction pattern of as-prepared $\mathrm{K}_{3} \mathrm{~V}_{2}\left(\mathrm{PO}_{4}\right)_{3}$ particles. The insets are the corresponding SEM and high angle annular dark field (HAADF) images with a schematic illustration of the structure. Reproduced with permission. ${ }^{74}$ Copyright 2019 Elsevier Ltd. (e) Charging and discharging profiles of $\mathrm{KVOPO}_{4}$ material in the voltage window of 2.0-5.0 V in $1 \mathrm{M} \mathrm{KPF}_{6} / \mathrm{EC}: \mathrm{PC}(1: 1 \mathrm{v} / \mathrm{v})$ electrolyte. Reproduced with permission. ${ }^{78}$ Copyright 2017, Royal Society of Chemistry. (f) Calculated theoretical voltage profile of $\mathrm{KVOPO}_{4}$ material with associated structures (insets). Reproduced with permission. ${ }^{79} \mathrm{Copyright} 2018$ Royal Society of Chemistry. (g) V K-edge XANES spectra and (h) EXAFS spectra of pristine $\mathrm{KVOPO}_{4}$ electrode. Reproduced with permission. ${ }^{80}$ Copyright 2018, Wiley-VCH.

cathode material. ${ }^{79}$ The calculated theoretical voltage profile is exhibited in Fig. $7 f$ with the $\mathrm{V}^{4+} / \mathrm{V}^{5+}$ redox couple. From the DFT study, multiple phase transitions are involved during $\mathrm{K}$ de/ intercalation, which introduced a $\sim 6.6 \%$ volume change. Low active energy barriers were calculated at the same time. In addition, Ding et al. reported that in the $\mathrm{KVPO}_{4}$ material, the $\mathrm{V}^{3+}$ $\leftrightarrow \mathrm{V}^{4+} \leftrightarrow \mathrm{V}^{5+}$ redox couples are fully electrochemically active in SIBs, and a high specific capacity of $235 \mathrm{~mA} \mathrm{~h} \mathrm{~g}^{-1}$ was achieved. ${ }^{80}$ Further V K-edge X-ray near edge structure (XANES) spectra and extended X-ray absorption fine structure (EXAFS) revealed that the first $\mathrm{Na}$ ion occupies the identical crystallographic sites that are emptied by the deintercalated $\mathrm{K}$ ion (Fig. $7 \mathrm{~g}$ and $\mathrm{h}$ ). Future work can be focused on improvement of the cycling stability of the $\mathrm{KVOPO}_{4}$ material and suitable carbonaceous decoration to upgrade its $C$-rate performance. ${ }^{\mathbf{8 1}}$ Other types of potassium-containing oxyphosphates are continuously emerging with distinctive electrochemical profiles, such as $\mathrm{K}_{2}\left[(\mathrm{VO})_{2}\left(\mathrm{HPO}_{4}\right)_{2}\left(\mathrm{C}_{2} \mathrm{O}_{4}\right)\right]$ reported by Liao et al. ${ }^{82}$ More relevant work should be urgently undertaken since these types of materials are likely to be important players in real applications of PIBs in the near future.

\subsection{Potassium-containing pyrophosphates}

Pyrophosphates are other important candidates as potential high-voltage potassium hosts, since they are common polyanionic compounds and have been widely studied for both LIBs and SIBs. ${ }^{83-85}$ In the case of PIBs, $\mathrm{KMoP}_{2} \mathrm{O}_{7}$ and $\mathrm{KVP}_{2} \mathrm{O}_{7}$ exhibited reversible potassium hosting capacities of $25 \mathrm{~mA} \mathrm{~h} \mathrm{~g}{ }^{-1}$ and $55 \mathrm{~mA} \mathrm{~h} \mathrm{~g}{ }^{-1}$ at $50{ }^{\circ} \mathrm{C}$, respectively. Although their capacity is relatively low according to the reported literature, they have the highest working voltage among all the existing potassium hosts. Higher cathode voltage is very useful for improving the overall energy density of PIBs. Park et al. also proposed an interesting material screening method, inorganic 
registry, for PIBs. ${ }^{86}$ They employed DFT calculations during a heuristics-based data-mining process. Six compounds, including $\quad \mathrm{KTiP}_{2} \mathrm{O}_{7}, \quad \mathrm{KVP}_{2} \mathrm{O}_{7}, \quad \mathrm{KMoP}_{2} \mathrm{O}_{7}, \quad \mathrm{~K}_{2}(\mathrm{VO})_{3}\left(\mathrm{P}_{2} \mathrm{O}_{7}\right)_{2}$, $\mathrm{K}_{2} \mathrm{MnP}_{2} \mathrm{O}_{7}$, and $\mathrm{KMnVO}_{4}$ were pinpointed as possessing high voltage platforms, and some of them even had higher platforms than 5.0 V. Park et al. systemically synthesized all the screened materials and collected their cyclic voltammograms, as shown in Fig. 8a. Interestingly, only those electrochemically active

(a)

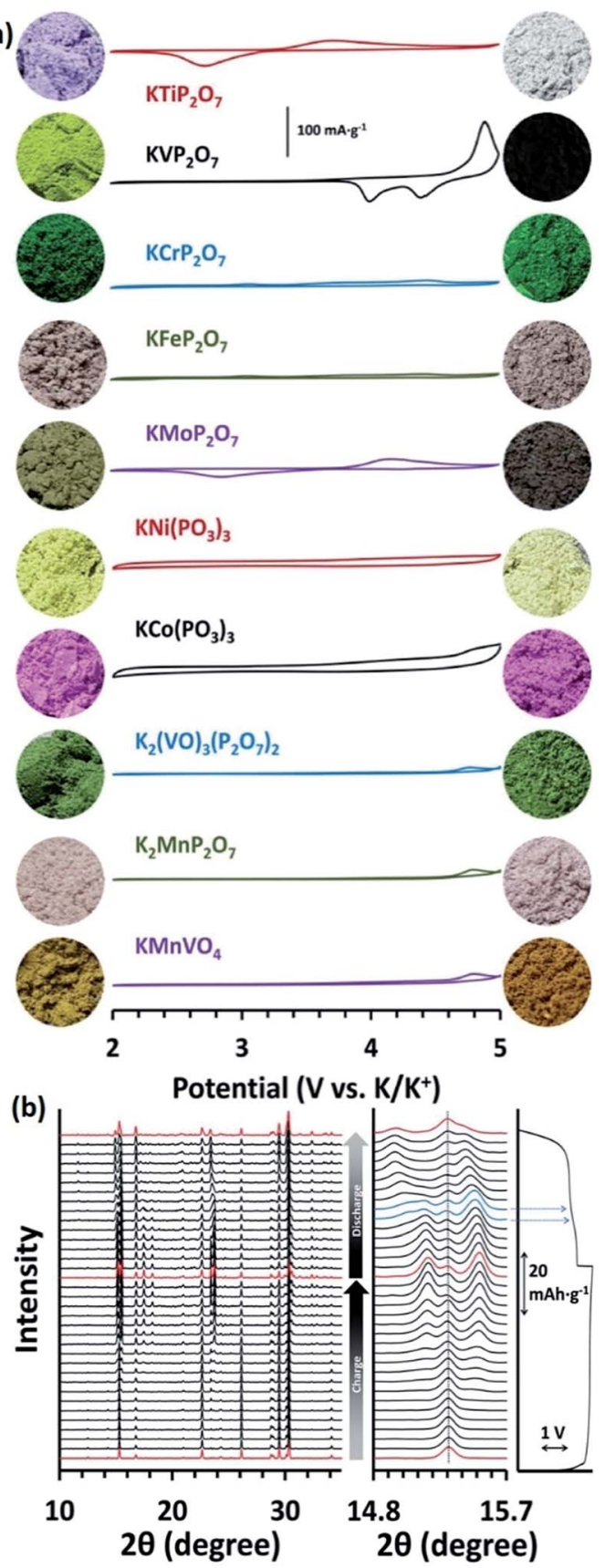

Fig. 8 (a) Cyclic voltammetry (CV) profiles of ten screened polyanionic compounds in $\mathrm{KPF}_{6} / \mathrm{EC}$ : diethyl carbonate (DEC) at $20^{\circ} \mathrm{C}$ and their corresponding colours before and after charging. (b) In situ XRD patterns of $\mathrm{KVP}_{2} \mathrm{O}_{7}$ material over one full cycle. Reproduced with permission. ${ }^{86}$ Copyright 2018, Wiley-VCH. materials (in the given voltage window) showed obvious colour changes. In addition, they performed in situ XRD with a full charge and discharge cycle. The enlarged XRD patterns in Fig. $8 \mathrm{~b}$ exhibit a continuous phase transformation from $P 2_{1} / c$ to $P \overline{1}$ with a certain type of $\mathrm{K}^{+} /$vacancy rearrangement.

In addition, $\mathrm{Fe}$ and $\mathrm{Mn}$-based pyrophosphates, such as $\mathrm{KFeP}_{2} \mathrm{O}_{7}$ and $\mathrm{K}_{2} \mathrm{MnP}_{2} \mathrm{O}_{7}$, possibly have voltage platforms higher than 5.0 V due to the strong inductive effect of $\mathrm{P}_{2} \mathrm{O}_{7}{ }^{4-}$. Hosaka et al. synthesized $\mathrm{K}_{2} \mathrm{FeP}_{2} \mathrm{O}_{7} / \mathrm{C}$ and $\mathrm{K}_{2} \mathrm{MnP}_{2} \mathrm{O}_{7} / \mathrm{C}$ electrodes, but only low reversible capacities and low voltage platforms could be achieved. ${ }^{16}$ They attributed these inferior electrochemical properties to the weak inductive effect that $\mathrm{FeO}_{4}$ tetrahedra can offer (compared to $\mathrm{FeO}_{6}$ octahedral coordination). Although $\mathrm{KVP}_{2} \mathrm{O}_{7}$ has a theoretical specific capacity of $102 \mathrm{~mA} \mathrm{~h} \mathrm{~g}{ }^{-1}$, the recently achieved capacity is lower than $60 \mathrm{~mA} \mathrm{~h} \mathrm{~g}{ }^{-1}$, which means that there is still large room for exploration.

\subsection{Potassium-containing fluorophosphates/fluorosulfates}

The participation of $\mathrm{F}$ in the $\mathrm{MO}_{6}(\mathrm{M}=\mathrm{V}, \mathrm{Fe}, \mathrm{Mn}$, etc. $)$ octahedra and $\mathrm{XO}_{4}$ groups $(\mathrm{X}=\mathrm{P}, \mathrm{S}$, etc. $)$ can effectively enhance the inductive effect of adjacent transition metal ions, which can offer higher working voltage platforms for various types of polyanionic alkali-metal-ion hosting compounds in LIBs and SIBs. ${ }^{68,87-90}$ In the case of PIBs, the participation of $\mathrm{F}$ in the open framework also provides great advantages in terms of higher voltages, higher rates of ionic diffusion, and enhanced structural stabilization. Chihara et al. first reported a new polyanionic compound, $\mathrm{KVPO}_{4} \mathrm{~F}$, as a promising cathode material for PIBs. ${ }^{78}$ The synthesised $\mathrm{KVPO}_{4} \mathrm{~F}$ material crystallized into orthorhombic symmetry with the space group Pna2 1 (as shown in Fig. 9a). An average voltage platform of $\sim 4.1 \mathrm{~V}$ was achieved with good $C$-rate performance (Fig. 9b and c). Then, Kim et al. developed a new strategy for the stoichiometric $\mathrm{KVPO}_{4} \mathrm{~F}$ material. ${ }^{91}$ Two distinctive $\mathrm{K}$ ion sites were identified through Rietveld refinements, which are shown in Fig. 9d. The as-obtained material could exhibit a reversible capacity of $\sim 105 \mathrm{~mA} \mathrm{~h} \mathrm{~g}{ }^{-1}$ with a $\sim 4.2 \mathrm{~V}$ voltage platform. Four obvious oxidation/ reduction couples were recognised in the voltage range of $4.0 \mathrm{~V}$ to $5.0 \mathrm{~V}$ (Fig. 9e and $\mathrm{f}$ ). A high energy density of $450 \mathrm{~W} \mathrm{~h} \mathrm{~kg}{ }^{-1}$ was achieved and is displayed in Fig. 9g in comparison with other types of potassium hosts. Formation energy calculations indicated that the lowest energy configuration is less than $6 \mathrm{meV}$ above the convex hull. A XANES study revealed that the pristine sample only contains $\mathrm{V}^{3+}$. Therefore, the oxidation state of fully charged $\mathrm{KVPO}_{4} \mathrm{~F}$ is tetravalent. This $\mathrm{K}$-containing fluoride phosphate is a very important candidate for high energy PIBs and should receive more decent and comprehensive investigations in the near future..$^{92}$

Another important candidate for high energy PIBs is $\mathrm{K}_{3} \mathrm{~V}_{2}\left(\mathrm{PO}_{4}\right)_{2} \mathrm{~F}_{3}$. The electrochemically active $\mathrm{K}_{3} \mathrm{~V}_{2}\left(\mathrm{PO}_{4}\right)_{2} \mathrm{~F}_{3}$ cannot be directly synthesized via a sintering method, however, according to Lin et al., ${ }^{93} \mathrm{~K}_{3} \mathrm{~V}_{2}\left(\mathrm{PO}_{4}\right)_{2} \mathrm{~F}_{3}$ can be obtained from well-crystallized $\mathrm{Na}_{3} \mathrm{~V}_{2}\left(\mathrm{PO}_{4}\right)_{2} \mathrm{~F}_{3}$ through an electrochemical exchange process. The Rietveld refinement of $\mathrm{K}_{3} \mathrm{~V}_{2}\left(\mathrm{PO}_{4}\right)_{2} \mathrm{~F}_{3}$ is displayed in Fig. 9h. Also, the determined phase transition processes for each space group are illustrated in Fig. 9i. Two 
(a)

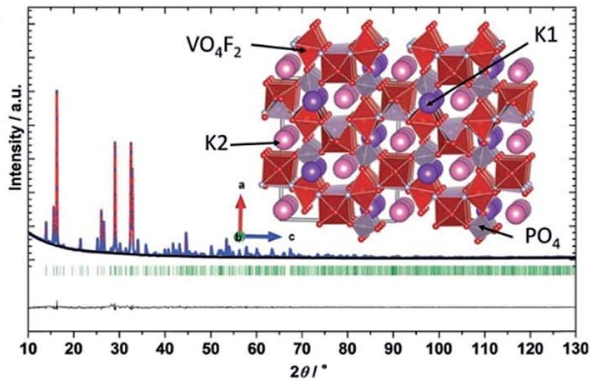

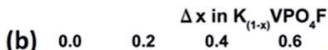

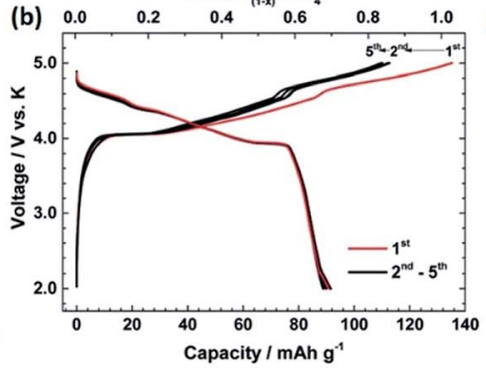

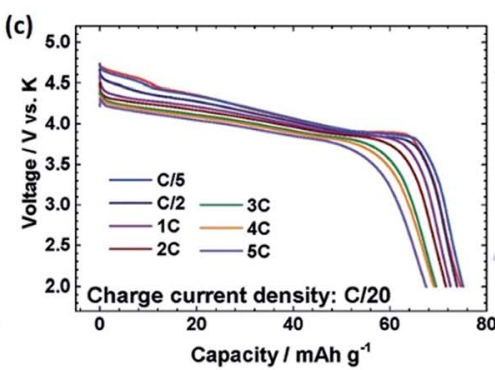
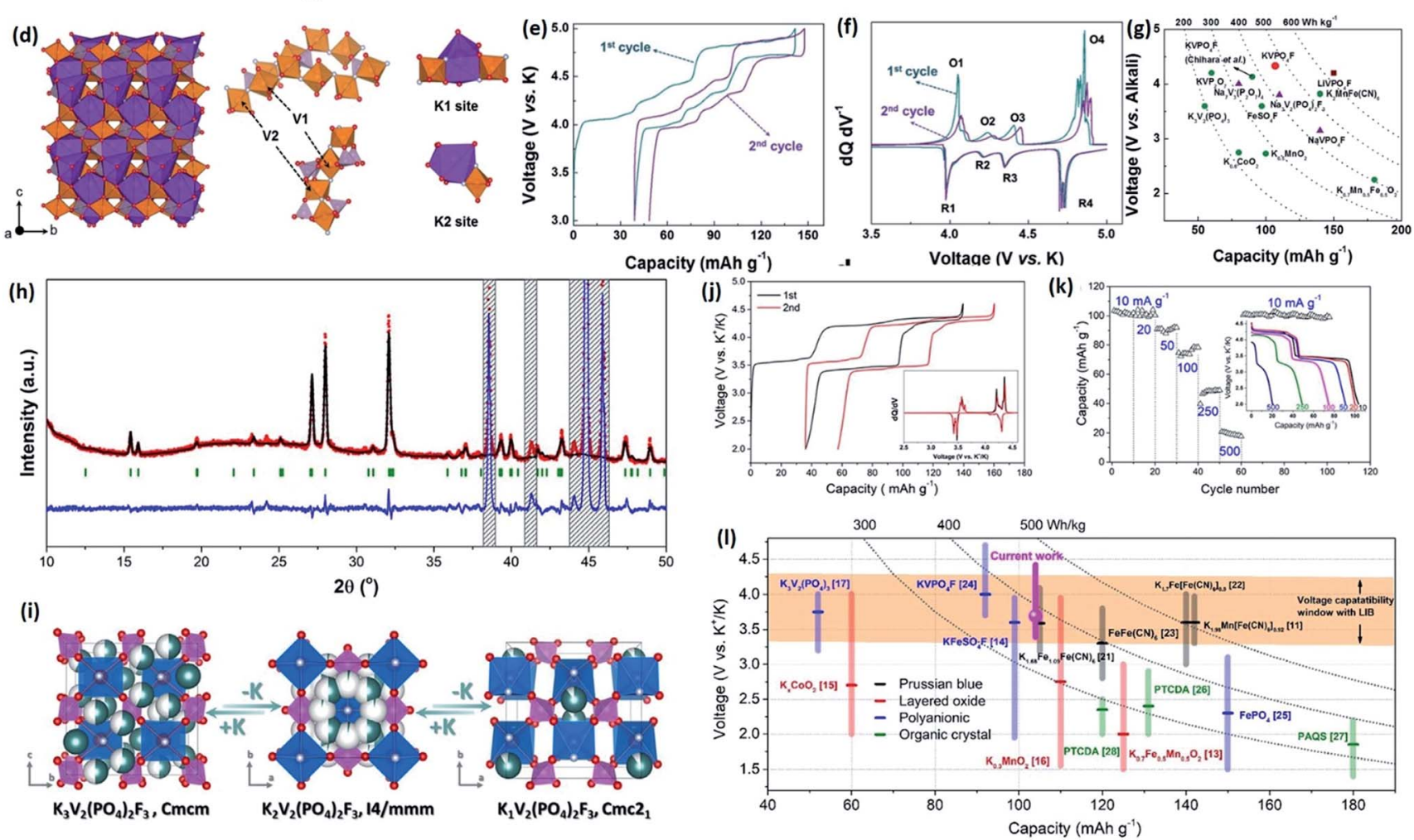

Fig. 9 (a) Rietveld refinement of the as-prepared $\mathrm{KVPO}_{4} \mathrm{~F}$ material, with the structure shown in the inset. (b) Electrochemical profiles of the initial five cycles of $\mathrm{KVPO}_{4} \mathrm{~F}$ at 5.0-2.0 V. (c) C-rate capability of $\mathrm{KVPO}_{4} \mathrm{~F}$. Reproduced with permission. ${ }^{78}$ Copyright 2017, Royal Society of Chemistry. (d) Schematic illustration and analysis of the structure of $\mathrm{KVPO}_{4} \mathrm{~F}$ with two different $\mathrm{K}$-ion sites. (e) First and second cycle voltage profiles of $\mathrm{KVPO}_{4} \mathrm{~F}$ at $5 \mathrm{~mA} \mathrm{~g}^{-1}$ and (f) corresponding differential capacity (dQ/dV plots. (g) Energy density comparison of various potential cathodes for PIBs. Reproduced with permission. ${ }^{91}$ Copyright 2018, Wiley-VCH. (h) Rietveld refinement result of as-prepared $\mathrm{K}_{3} \mathrm{~V}_{2}\left(\mathrm{PO}_{4}\right)_{2} \mathrm{~F}_{3}$ material. (i) Schematic illustrations of phase transition during $\mathrm{K}$ insertion and extraction. (j) Initial two charge and discharge $c u r v e s$ of $K_{3} V_{2}\left(P O_{4}\right)_{2} F_{3}$ and the corresponding $\mathrm{d} Q / \mathrm{d} V$ plot (inset). (k) Rate capabilities. (l) Summary and comparison of capacities and voltages of different types of reported cathode materials. Reproduced with permission. ${ }^{93}$ Copyright 2018, Elsevier.

obvious oxidation/reduction redox couples around $3.5 \mathrm{~V}$ and $4.25 \mathrm{~V}$ are clearly revealed (Fig. 9j). Relatively good $C$-rate performance is also displayed in Fig. 9k with a capacity of $\sim 80 \mathrm{~mA} \mathrm{~h} \mathrm{~g}^{-1}$ at $0.1 \mathrm{~A} \mathrm{~g}^{-1}$. Fig. 91 shows the energy density level that $\mathrm{K}_{3} \mathrm{~V}_{2}\left(\mathrm{PO}_{4}\right)_{2} \mathrm{~F}_{3}$ can achieve, making it highly competitive with the Prussian blue analogues and organic crystals. This work is important in the PIB research field, since other types of cathodes for SIBs can possibly be electrochemically active in PIBs and deserve more intense exploration.

Fluorosulfates have attracted much attention for LIBs and SIBs in the last five years. ${ }^{94-96}$ The partial substitution of F into the coordinated $\mathrm{O}$ sites can increase the inductive effect of adjacent transition metals, resulting in more electrostatic repulsion during the diffusion of alkali ions and leading to elevated de-/intercalation voltage platforms. Recham et al. first investigated the potential performances of $\mathrm{KFeSO}_{4} \mathrm{~F}$ in LIBs, SIBs, and PIBs. Similar structural relationships were identified for the K-based fluorosulfates when $\mathrm{K}$ was electrochemically replaced by $\mathrm{Li}$ or $\mathrm{Na}^{87} \mathrm{~A}$ high voltage platform of $\sim 3.9 \mathrm{~V}$ was achieved. Then, Lander $e$ al. further investigated the structural, electrochemical, and magnetic properties of $\mathrm{KFeSO}_{4} \mathrm{~F}$ polymorphs. ${ }^{97}$ They found that two main phases can be generated after an annealing process at $310{ }^{\circ} \mathrm{C}$ : monoclinic $\mathrm{KFeSO}_{4} \mathrm{~F}$ phase and orthorhombic $\mathrm{KFeSO}_{4} \mathrm{~F}$. Substitution with $\mathrm{Mn}$ and $\mathrm{Cu}$ both failed, since no pure phases could be obtained. The bond valence energy landscape (BVEL) revealed that the 
monoclinic $\mathrm{KFeSO}_{4} \mathrm{~F}$ is a $2 \mathrm{D}$ diffusion conductor while orthorhombic $\mathrm{KFeSO}_{4} \mathrm{~F}$ is a $3 \mathrm{D}$ diffusion conductor with a low energy barrier of $0.40 \mathrm{eV}$. A high theoretical energy density of $550 \mathrm{~W} \mathrm{~h} \mathrm{~kg}{ }^{-1}$ was proposed once the pure polymorphic phase was ascertained. Hosaka et al. recently has made significant progress in the determination of various phases produced at different sintering temperatures (Fig. 10a and b). ${ }^{16}$ By adjusting the electrolyte $\left(5.5 \mathrm{~mol} \mathrm{~kg}^{-1}\right.$ potassium bis(fluorosulfonyl) amide (KFSA)/diglyme vs. $1 \mathrm{M} \mathrm{KPF}_{6} / \mathrm{EC}: \mathrm{PC}$ ), much improved cycling stability was achieved, as shown in Fig. 10c and d. operando XRD also indicates a reversible structural change from $\mathrm{KFeSO}_{4} \mathrm{~F}$ (space group $\mathrm{Pna}_{1}$ ) to the $\mathrm{FeSO}_{4} \mathrm{~F}$ space group (Pnna). The operando XRD pattern is displayed in Fig. 10e. A multiphase transition was recognised and should receive more comprehensive investigation, as well as more strategies for improving the electrochemical performance.

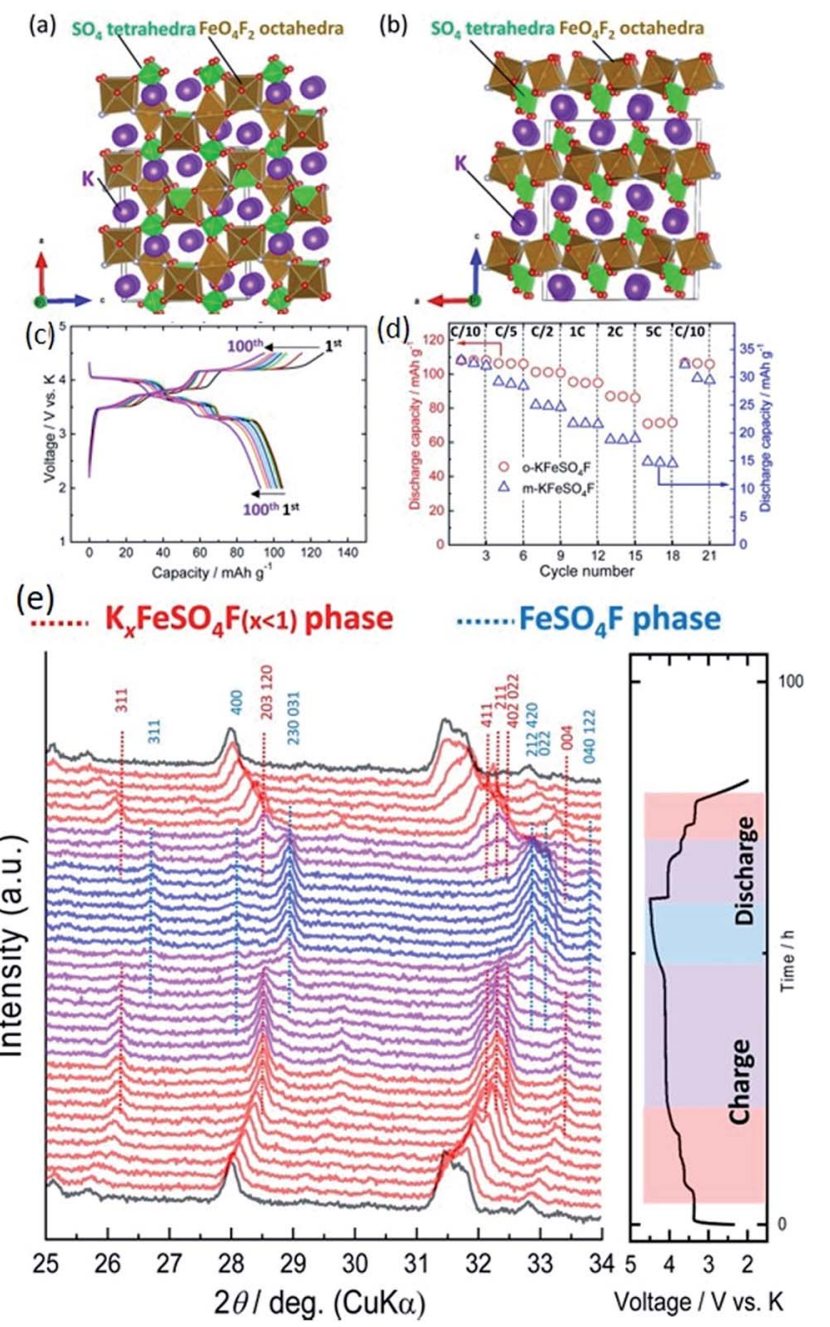

Fig. 10 Schematic illustrations of (a) orthorhombic $\mathrm{KFeSO}_{4} \mathrm{~F}$ and (b) monoclinic $\mathrm{KFeSO}_{4} \mathrm{~F}$ phase. (c and d) Their corresponding electrochemical performances in $5.5 \mathrm{~mol} \mathrm{~kg}^{-1} \mathrm{KFSA}$ /diglyme (G2) electrolyte. (e) Operando XRD patterns of orthorhombic $\mathrm{KFeSO}_{4} \mathrm{~F}$ electrode during the initial cycle in a PIB. Reproduced with permission. ${ }^{16}$ Copyright 2019, Chemical Society of Japan \& Wiley-VCH.
In general, most polyanionic compounds possess higher voltage platforms (above $3.5 \mathrm{~V}$ vs. $\mathrm{K} / \mathrm{K}^{+}$), and therefore, their energy densities are even highly comparable to those of some Licathodes. It is important to put an emphasis on these polyanionic K-cathode compounds towards the real application of advanced PIBs. In order to alleviate the existing drawbacks such as low theoretical capacity and sluggish kinetics of polyanionictype materials for PIBs, it is important to expand the existing crystalline structures with well-designed carbon matrices. In addition, discovering more double redox reaction transition metal ions, such as $\mathrm{Mn}^{2+} / \mathrm{Mn}^{3+} / \mathrm{Mn}^{4+}, \mathrm{V}^{3+} / \mathrm{V}^{4+} / \mathrm{V}^{5+}$, and $\mathrm{Co}^{2+} /$ $\mathrm{Co}^{3+} / \mathrm{Co}^{4+}$, is one of the key tasks in the exploration of compounds with increased theoretical capacities.

\section{Organic compounds as advanced potassium hosts}

Organic compounds have been considered as attractive cathode candidates for SIBs due to their low cost and flexible structures. ${ }^{98-101}$ In the case of PIBs, their weak intermolecular interactions can benefit the intercalation of large $\mathrm{K}^{+}$ions. Moreover, the merits of various structures, and the low cost and versatile chemistry of these organic compounds have attracted great interest for PIBs in the last few years. The functional groups that account for electrochemically active oxidation/reduction play key roles and have been subjected to careful characterization. Therefore, it is necessary to provide a detailed summary of their distinctive structures and properties.

\subsection{Non-metal-containing organic compounds}

Non-metal-containing organic compounds are starting materials utilized as electrode materials in LIBs and SIBs due to their low cost, high abundance, environmental friendliness, and amazing structural diversity. ${ }^{\mathbf{1 0 2 , 1 0 3}}$ Fan et al. introduced 3,4,9,10perylene-tetracarboxylic acid-dianhydride (PTCDA) as a potential cathode material for PIBs. ${ }^{\mathbf{1 0 4}}$ The $\mathrm{C}=\mathrm{O}$ bonds in PTCDA can be transformed to $\mathrm{C}-\mathrm{O}-\mathrm{M}(\mathrm{M}=\mathrm{Li}, \mathrm{Na}, \mathrm{K})$ during electrochemical processes. Due to its low electrical conductivity and solubility, however, the electrochemical performance of PTCDA in PIBs is not so satisfactory. They annealed PTCDA at a temperature designed to enhance its electrical conductivity without thermal decomposition (Fig. 11a). A capacity of $131 \mathrm{~mA} \mathrm{~h} \mathrm{~g}^{-1}$ in the voltage range of $1.5-3.5 \mathrm{~V}$ was achieved.

A reversible capacity of $60 \mathrm{~mA} \mathrm{~h} \mathrm{~g}{ }^{-1}$ could be obtained at high current density $\left(1 \mathrm{~A} \mathrm{~g}^{-1}\right.$ ) (Fig. $11 \mathrm{~b}$ and c). Ex situ XRD indicated that most peaks could be restored. There are also many other organic compounds under intensive exploration. Gao et al. developed a polyaniline cathode with a polymer-gel electrolyte for high-energy-density PIBs. ${ }^{105}$ The structure of this cross-linked poly(methyl methacrylate) (PMMA) is shown in Fig. 11d and e. A high reversible voltage platform around $3.0 \mathrm{~V}$ was achieved with a high capacity of $130 \mathrm{~mA} \mathrm{~h} \mathrm{~g}{ }^{-1}$, so that its energy density is highly competitive with those of other types of cathodes for PIBs, as shown in Fig. 11f and g. Recently, Jian et al. introduced another organic compound, poly(anthraquinonyl sulfide) (PAQS) as a novel cathode material for 

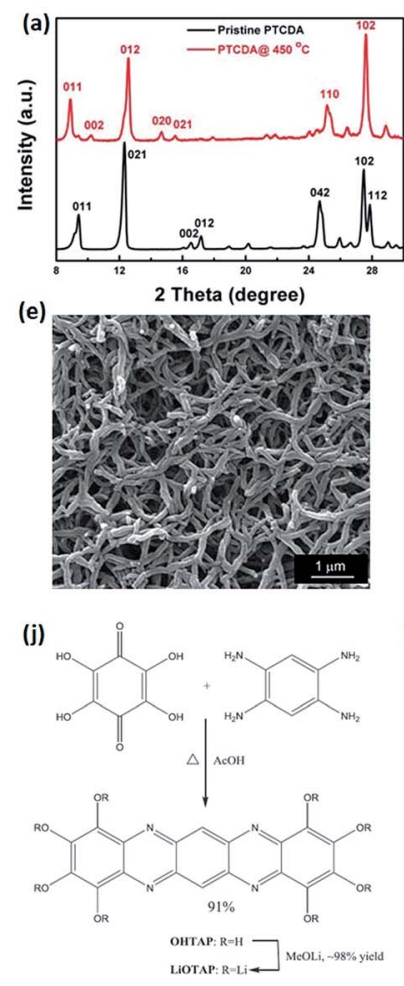
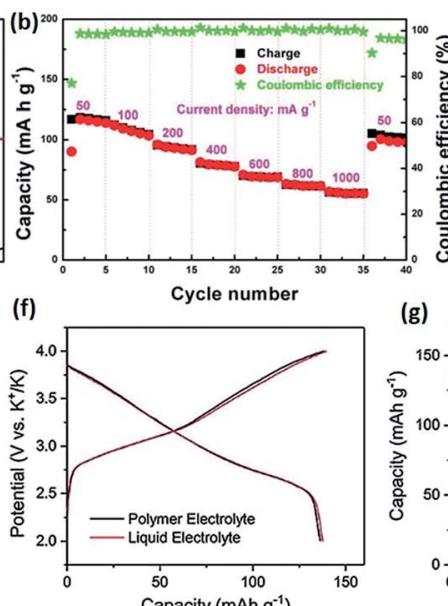

(k)

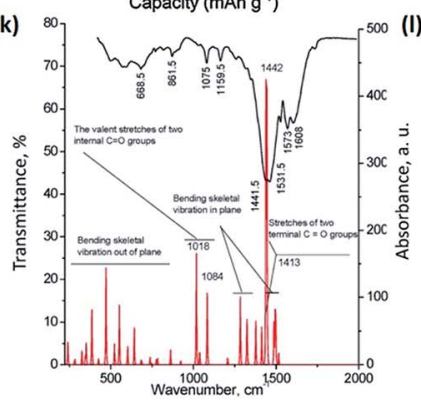

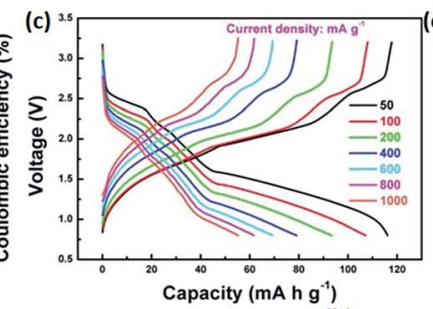

(g)

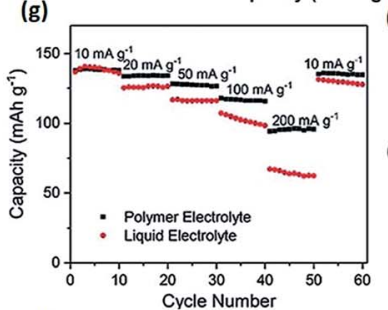

(h)

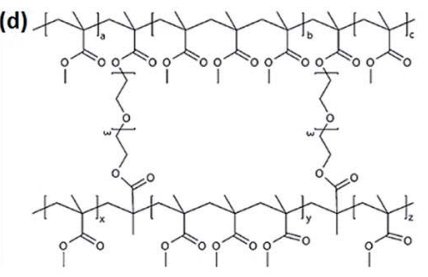

(i)

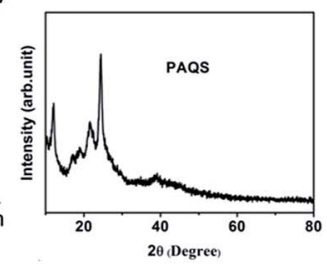

(m)

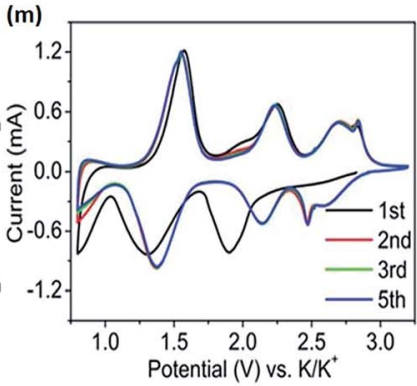

Fig. 11 (a) XRD patterns of pristine PTCDA and PTCDA after sintering. (b) Rate performance and (c) charge/discharge profiles at different current densities of sintered PTCDA. Reproduced with permission. ${ }^{104}$ Copyright 2018, Wiley-VCH. (d) The chemical structure of the cross-linked PMMA. (e) SEM image of the as-obtained PMMA. (f and g) Charge/discharge profiles and C-rate performance of polyaniline cathode. Reproduced with permission. ${ }^{105}$ Copyright 2018, Wiley-VCH. (h) Chemical structure and (i) XRD pattern of PAQS. Reproduced with permission. ${ }^{23}$ Copyright 2016 , Elsevier. (j) Schematic illustration of the synthesis of OHTAP and tetrahydroxycyclohexa-2,5-diene-1,4-dione (LiOTAP). (k) The experimental and simulated FTIR spectra of LiOTAP. Reproduced with permission. ${ }^{106}$ Copyright 2019, Elsevier. (l) The theoretical electrochemical reactions of PPTS in PIBs. (m) The initial five CV curves of PPTS. Reproduced with permission. ${ }^{107}$ Copyright 2019 , the Royal Society of Chemistry.

PIBs. ${ }^{23}$ Its chemical structure and corresponding XRD patterns are shown in Fig. $11 \mathrm{~h}$ and i. The PAQS material was prepared by a modified Phillips method. There are two carbonyl groups in one monomer. Upon charging, two $\mathrm{K}$ ions can be intercalated with two $\mathrm{C}=\mathrm{O}$ sites, corresponding to two distinctive working platforms in the electrochemical profile. Very recently, Slesarenko et al. reported a new tetraazapentacene-based redox-active material for PIBs. ${ }^{106}$ The facile synthesis of octahydroxytetraazapentacene (OHTAP) is displayed in Fig. 11j. Detailed analysis of the Fourier transform infrared (FTIR) spectrum is also shown in Fig. 11k, indicating its virtually insoluble property, very different from all common organic solvents. High capacities over $200 \mathrm{~mA} \mathrm{~h} \mathrm{~g}{ }^{-1}$ could be achieved in the initial cycles, but its cycling stability is not very satisfactory upon extended cycling. Also, its coulombic efficiency is below $90 \%$ for each cycle, which may hinder its further application. Another sulfide-type organic compound, poly(pentacenetetrone sulfide) (PPTS), was successfully synthesized by Tang et al. and recently introduced as an organic cathode. ${ }^{107}$ It can sustain three $\mathrm{K}^{+}$ion intercalations with three distinctive oxidation/reduction peaks, which is shown in Fig. 111 and m. A solid-electrolyte interphase (SEI) layer was confirmed via decomposition of dimethoxyethane (DME) and $\mathrm{KPF}_{6}$, and its $d$-spacing was slightly increased after cycling, which is due to the insertion of $\mathrm{K}$ ions.
Unexceptional high capacity was achieved $\left(\sim 260 \mathrm{~mA} \mathrm{~h} \mathrm{~g}{ }^{-1}\right.$ at $0.1 \mathrm{~A} \mathrm{~g}^{-1}$ ), and even when cycled at 10C, it still had a discharge capacity of $160 \mathrm{~mA} \mathrm{~h} \mathrm{~g}{ }^{-1}$. This material shows promising potential for real applications in PIBs since it possesses superior electrochemical properties with acceptable voltage platforms.

In the meantime, other researchers continuously explore novel organic compounds for advanced PIBs. For example, Tian et al. synthesized carbonyl-based polyimide and polyquinoneimide with one-dimensional (1D) and 2D structures for PIBs. ${ }^{108}$ Among them, polyquinoneimide showed the highest initial capacity because of its multiple carbonyl groups. The cycling stability largely depends on the $\pi$-conjugation structure, and the distribution density of carbonyl groups will account for this. Vitamin K also showed potentials in Xue et al.'s work. ${ }^{109}$ Vitamin $\mathrm{K}$ is an essential nutrient for the human body, and it also possesses a high theoretical specific capacity of $313.5 \mathrm{~mA} \mathrm{~h} \mathrm{~g}^{-1}$. After hybridization with graphene nanotubes, more stable cycling performance was achieved. This can be ascribed to its enhanced electronic conductivity and soluble nature. Conjugated microporous polymers (CMPs) also came to our attention, since their lowest unoccupied molecular orbitals (LUMOs) are well distributed and easily controlled..$^{110} \mathrm{~A}$ possible $\mathrm{K}$ storage mechanism was proposed at the same time. An acyclic 
compound, 2,20-azobis(2-methylpropionitrile) (AIBN), also shows potential potassium hosting capability as an anode. ${ }^{111}$ It can offer a capacity of over $160 \mathrm{~mA} \mathrm{~h} \mathrm{~g}{ }^{-1}$ in the voltage window of $0.01 \mathrm{~V}$ to $3.0 \mathrm{~V}$. More importantly, the electrochemical active sites $\mathrm{N}=\mathrm{N}$ and $\mathrm{C}=\mathrm{N}$ only have trace toxicity.

It is satisfying to summarize the non-metal containing compounds for PIBs, since their structural diversity is really impressive, and different functional groups are unique in their distinctive electrochemical profiles. More and more types of organic compounds are continuously being discovered and explored. ${ }^{103,112-117}$ In addition, there are still some obstacles for these types of compounds that need to be addressed, such us further improving the cycling stability and operating voltage platform, while endowing them with less toxicity, higher coulombic efficiency, etc.

\subsection{Metal-containing organic compounds}

Organic compound cathodes that contain either transition metal ions or alkali ions are more significant, since the utilization of graphite anode can possibly be achieved for practical application. Therefore, it is necessary to focus on the metal containing organic compounds and continuously explore their further potential. Zhao et al. obtained oxocarbon salts $\left(\mathrm{M}_{2}(\mathrm{CO})_{n}\right)$
$(\mathrm{M}=\mathrm{Li}, \mathrm{Na}, \mathrm{K} ; n=4,5,6)$ through a one-pot proton exchange reaction. ${ }^{118}$ The structures of these organic oxocarbon salts, as well as their preparation procedures, are shown in Fig. 12a. These types of structures are unique and can be similarly expanded. Most oxocarbon salts are soluble in commonly used organic electrolytes. In Fig. 12b, the initial discharge capacity with regard to the available active carbonyls is summarized. High capacities could be obtained when $\mathrm{K}_{2} \mathrm{C}_{5} \mathrm{O}_{5}$ and $\mathrm{K}_{2} \mathrm{C}_{6} \mathrm{O}_{6}$ were presented. The authors further explored the possible potassium storage mechanism via in situ Raman spectroscopy (Fig. 12c and d). The ring vibrations remained stable while those of the carbonyl functional groups decreased during charging. High reversibility was confirmed via representations of the vibrations of both rings and carbonyl groups. Zhao et al. reported a novel anthraquinone with substituted sodium sulfonate groups as an organic material for PIBs. Anthraquinone-1,5disulfonic acid sodium salt was the final product with good capacity retention. ${ }^{\mathbf{1 1 9}}$ They also proposed a two-electron transfer process, as shown in Fig. 12e. Wang et al. successfully synthesized potassium perylene-3,4,9,10-tetracarboxylate $\left(\mathrm{K}_{4} \mathrm{PTC}\right)$ as a stable organic anode for PIBs. ${ }^{120}$ This material was obtained by treating PTCDA with $\mathrm{KOH}$ in ethanol solution. The typical charge/discharge profiles in the first three cycles of $\mathrm{K}_{4} \mathrm{PTC}$ are displayed in Fig. 12f. Its purity and synthesis procedure are
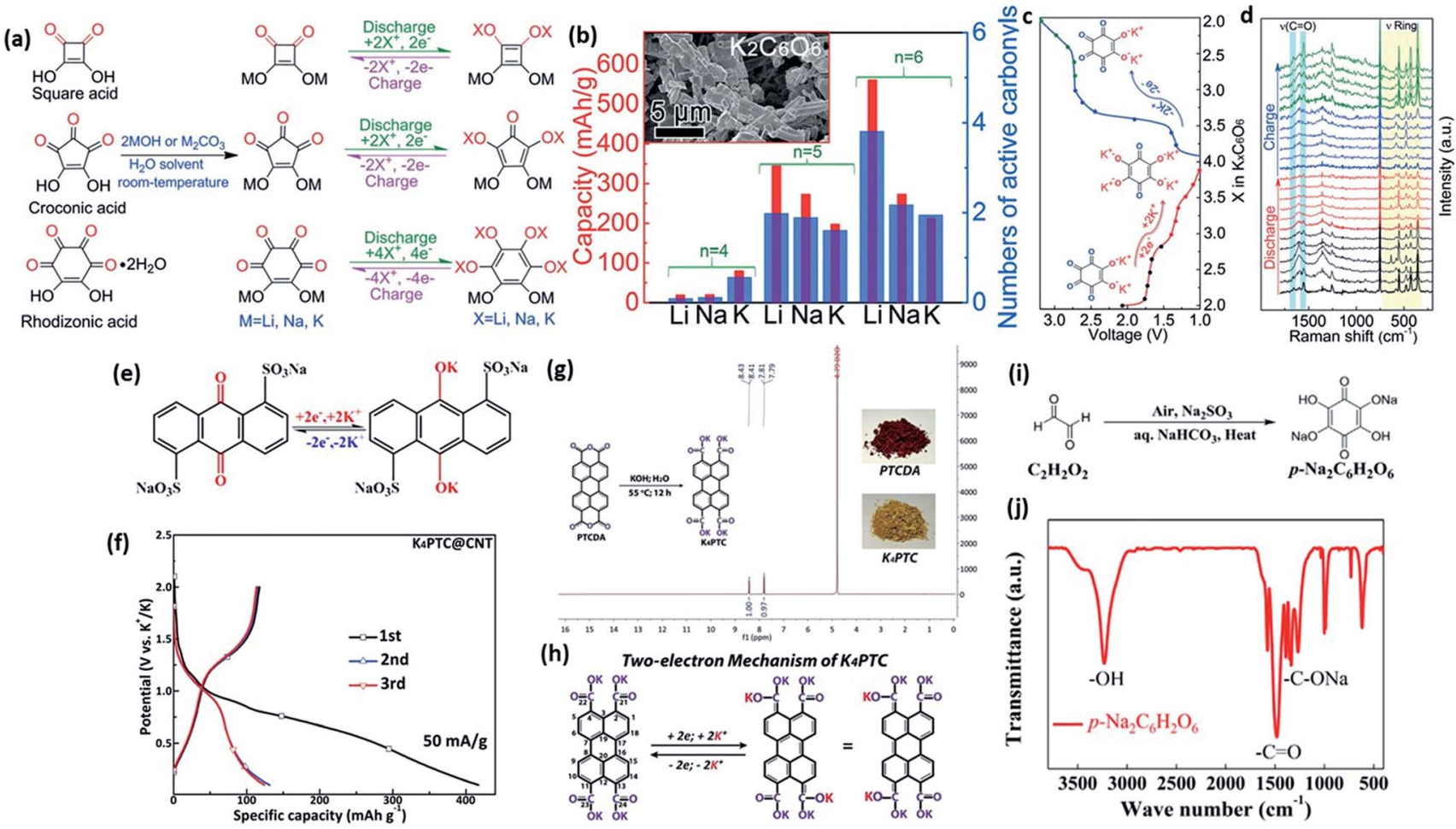

(h)
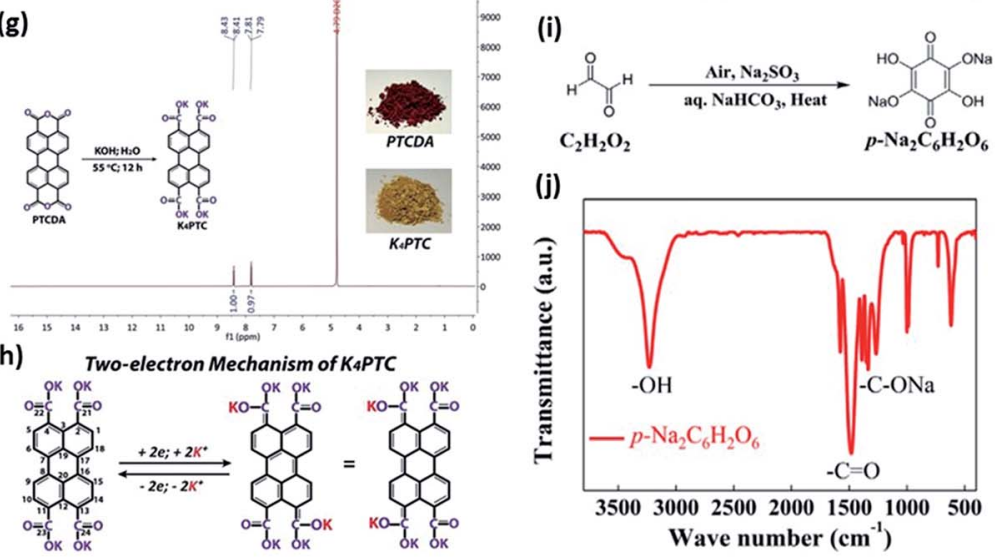

Fig. 12 (a) Schematic diagrams of synthesis processes, structures, and theoretical reactions of the obtained oxocarbon salts. (b) The available discharge capacity and corresponding functional carbonyl groups. The inset is an SEM image of $\mathrm{K}_{2} \mathrm{C}_{6} \mathrm{O}_{6}$. (c) Discharge/charge profile of $\mathrm{K}_{2} \mathrm{C}_{6} \mathrm{O}_{6}$ with marked points for PIBs and (d) corresponding in situ Raman spectra. Reproduced with permission. ${ }^{118} \mathrm{Copyright} \mathrm{2016,} \mathrm{Wiley-VCH}$. (e) The possible potassium storage mechanism of anthraquinone-1,5-disulfonic acid sodium salt. Reproduced with permission. ${ }^{119}$ Copyright 2017 , Elsevier. (f) The initial three charge/discharge curves of the as-prepared $\mathrm{K}_{4}$ PTC@CNT electrode. (g) The synthesis process for the $\mathrm{K}_{4} \mathrm{PTC}(\mathrm{aCNT}$ composite and its ${ }^{1} \mathrm{H}$ nuclear magnetic resonance (NMR) spectrum in $\mathrm{D}_{2} \mathrm{O}$. (h) The proposed two-electron mechanism of the $\mathrm{K}_{4} \mathrm{PTC}(\mathrm{aCNT}$ electrode in PIBs. Reproduced with permission. ${ }^{120}$ Copyright 2019, the Royal Society of Chemistry. (i) Synthesis process for the as-obtained $p$ $\mathrm{Na}_{2} \mathrm{C}_{6} \mathrm{H}_{2} \mathrm{O}_{6}$ material. (j) FTIR spectrum of the $p-\mathrm{Na}_{2} \mathrm{C}_{6} \mathrm{H}_{2} \mathrm{O}_{6}$ material. Reproduced with permission. ${ }^{124}$ Copyright 2019, Elsevier. 
introduced in Fig. 12g. Only two H signals can be detected, and no PTCDA signal appeared (Fig. 12g). It also displays excellent $C$-rate performance, which can be ascribed to the low energy gap between the highest occupied molecular orbital (HOMO) and LUMO levels based on the DFT calculations. They also proposed a two-electron mechanism for $\mathrm{K}_{4} \mathrm{PTC}$, as shown in Fig. 12h. Liang et al. developed azobenzene-4,4'-dicarboxylic acid potassium salts (ADAPTS) as a cathode material for high performance PIBs. ${ }^{121}$ ADAPTS is connected with two $\mathrm{N}$ atoms (azo group, $\mathrm{N}=\mathrm{N}$ ), which is also the main redox centre for the overall charge density distribution. One voltage platform was observed in the charge/discharge profiles and CV curves. Similarly, Li et al. introduced a conjugated dicarboxylate derivative, potassium naphthalene-2,6-dicarboxylate ( $\left.\mathrm{K}_{2} \mathrm{NDC}\right)$. This material has an aromatic naphthyl skeleton, and they used it as a potential organic anode for PIBs. ${ }^{122}$ This material possessed a low voltage platform at around $0.55 \mathrm{~V}$ and a relatively high specific capacity of $200 \mathrm{~mA} \mathrm{~h} \mathrm{~g}^{-1}$. Ex situ FTIR spectra indicated highly reversible two-electron electrochemical behaviour. The feasible chemical structure of this type of compound also makes it possible to introduce cobalt(II) into an organic anode for PIBs. ${ }^{123}$ A capacity around $200 \mathrm{~mA} \mathrm{~h} \mathrm{~g}{ }^{-1}$ was achieved. Its cycling performance and the coulombic efficiency of each cycle were still not sufficient, however. Pre-sodiation can be considered as an efficient approach to ameliorate this problem. Chen et al. introduced para-disodium-2,5-dihydroxy-1,4benzoquinone $\left(p-\mathrm{Na}_{2} \mathrm{C}_{6} \mathrm{H}_{2} \mathrm{O}_{6}\right)$, benefiting from salinization (Fig. 12i). ${ }^{\mathbf{1 2 4}}$ This material displayed much improved electrochemical performance, with a capacity of $121 \mathrm{~mA} \mathrm{~h} \mathrm{~g}^{-1}$ as well as good cycling stability over 50 cycles at $0.1 \mathrm{C}$. The presence of $\mathrm{Na}$ in the $p-\mathrm{Na}_{2} \mathrm{C}_{6} \mathrm{H}_{2} \mathrm{O}_{6}$ structure stabilized the energy distribution as well as suppressed the solubility of the electrode (Fig. 12j). Other researchers have also made great efforts to explore the possibilities of these metal-containing organic compounds for PIBs.

Organic compounds have shown promising aspects for the real application of PIBs since their theoretical capacities are the highest among all the types of cathodes. They also possess relatively high voltage platforms, and further discoveries of satisfactory electrodes can be reasonably anticipated due to their feasible and versatile chemical structures. Their distinctive chemical structures also offer great potential for using them as anode materials as well, such as $\mathrm{K}_{4}$ PTC mentioned above in Fig. 12f. While using them as anode materials, it is important to pay extra attention to their ICE and reaction mechanisms. Rate performance can be improved with appropriate designs of the carbon matrix. Nevertheless, several problems should be urgently outlined and emphasised. The operation voltages are still not high enough for goals of high energy densities of PIBs. It is important to continuously design and fabricate other types of organic compounds with feasible structures and higher electrostatic repulsion. Focusing on the solubility-related problems and initial coulombic efficiency (ICE) improvement should be first considered. Also, there should be an emphasis on potassium containing organic compounds, so that the use of graphite anode can be applied in practical applications of PIBs.

\section{Summary and future perspectives}

Intensive attention has been paid to advanced potassium-ion batteries with low-cost, high energy density, and long-cycling life in recent years since they are considered as the alternative energy storage systems to replacing LIBs for portable electronic devices and electric vehicle applications in the near future. ${ }^{\mathbf{1 2 5 - 1 3 3}}$ Due to the low cost and abundance of $\mathrm{K}$ resources, it is worth making great efforts to investigate the appropriate electrode materials with high energy densities and satisfactory $C$-rate performance. ${ }^{\mathbf{1 3 4 , 1 3 5}}$ Benefiting from the similarities between PIBs and SIBS/LIBs, rapid progress of both cathode and anode materials has been achieved to date. Due to the large radius of $\mathrm{K}^{+}$ions, however, previously well-recognised electrochemical reaction mechanisms in LIBs/SIBs are different from that of PIBs, so that specific investigations are needed. In addition, since graphite has been proved to be the most successful $\mathrm{K}^{+}$ion host, the main obstacles are found on the cathode side. Complex electrochemical behaviour, structural evolution, and corresponding reaction mechanisms occur during the Khosting process. Therefore, we have mainly focused on the cathode materials, especially the polyanionic-based materials and organic materials, which possess the merits of high operating voltages, large theoretical capacities, and versatile chemical structures. These parameters are important for the improvement of the overall energy densities of full PIBs.

Polyanionic-based compounds for PIBs have been intensively investigated in recent years. They commonly possess a 3D open framework and $1 \mathrm{D}$ to $3 \mathrm{D} \mathrm{K}^{+}$diffusion channels, and almost all the polyanionic-based compounds only suffer from low or at most tiny volume changes during cycling, which is an important factor for long-term cycling stability. The introduction of $\mathrm{F}$ and $\mathrm{S}$ can effectively enhance the inductive effect between adjacent atoms so that the operating voltage can be elevated. The synthesis processes for polyanionic-based compounds are facile and easy to control. Further studies related to the expansion of composition and structural space are urgently required. Most K-containing polyanionic cathodes are based on vanadium, and their range should be further expanded with other transition metals such as Mn and Fe. In addition, some of the reported materials only exhibit the oneelectron transfer mechanism, which represents half of their theoretical capacities. The second platform of these composites is possibly over $5 \mathrm{~V}$, which is out of the range of conventional organic electrolytes. A strategy involving combination with a solid electrolyte is worth the attempt.

Organic compounds are abundant and environmentally friendly with versatile chemical structures, and they are considered as promising cathode materials for PIBs as well. The functional groups that account for electrochemically active oxidation/reduction play key roles and have been subjected to careful characterization. Various carbonyls possess K-hosting capabilities based on different energy distributions. Large theoretical capacities are the main advances that have occurred for organic compounds, which is a key parameter for the improvement of energy density for PIBs. Future work should 


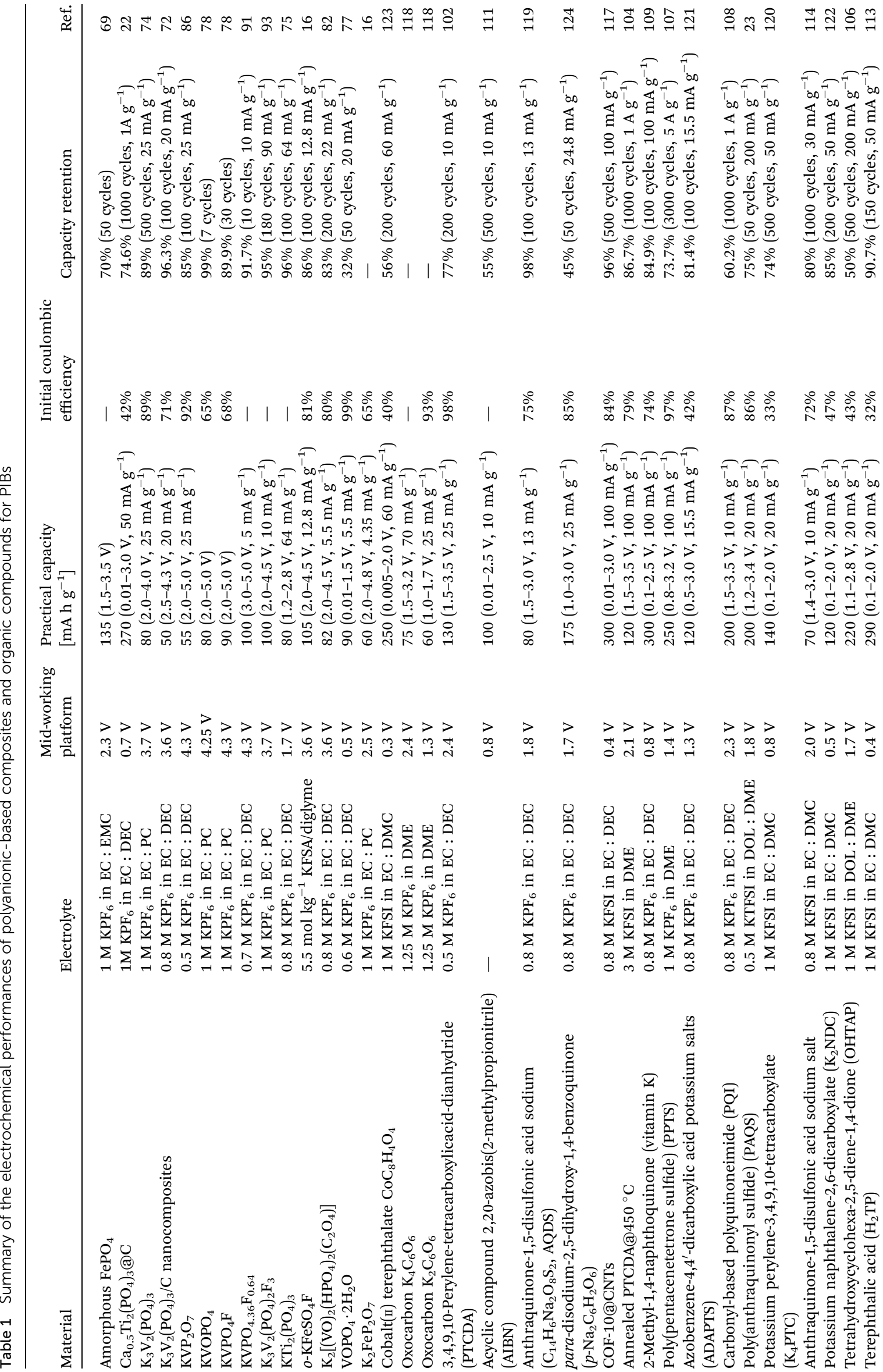


firstly address the problem of dissolution in conventional organic electrolytes, which will largely ameliorate the poor capacity retention. The operating voltages of organic cathodes for PIBs are also relatively low. The participation of transition metal elements can be considered as an effective way to increase both the electrostatic repulsion and van der Waals interaction forces. Also, the initial cycle coulombic efficiencies should be considered simultaneously, and the K-containing organic compounds should be given priority for further investigations.

In Table 1, we have summarized the achieved specific capacities, mid-working voltages, initial cycle coulombic efficiencies, and cycling stabilities of recently reported polyanionic composites and organic compounds for advanced PIBs. Further investigations should focus on addressing their existing specific limitations. With the obvious merits that we have mentioned above, we expect that the polyanionic composites and organic compounds are better choices for PIB cathodes than existing alternatives. Nevertheless, their manufacturing costs and need for a dry-room and controlled atmosphere should be further taken into consideration. The all-solid-state PIBs can be regarded as a promising way to solve the safety issues. More electrochemically active redox elements in polyanionic composites and more balanced chemical structures in organic compounds are key developing fields. We believe that studies targeted at the full cell configurations will also be taken seriously towards the real application of PIBs in the near future.

\section{Conflicts of interest}

There are no conflicts to declare.

\section{Acknowledgements}

This work was funded by The Science and Technology Development Fund, Macau SAR (Grant No. 0057/2019/A1 and 0092/ 2019/A2).

\section{References}

1 M. Armand and J.-M. Tarascon, Nature, 2008, 451, 652-657.

2 B. Dunn, H. Kamath and J.-M. Tarascon, Science, 2011, 334, 928-935.

3 D. Larcher and J. M. Tarascon, Nat. Chem., 2015, 7, 19-29.

4 J. M. Tarascon, Nat. Chem., 2010, 2, 510.

5 Z. P. Cano, D. Banham, S. Ye, A. Hintennach, J. Lu, M. Fowler and Z. Chen, Nat. Energy, 2018, 3, 279-289.

6 J. Y. Hwang, S. T. Myung and Y. K. Sun, Chem. Soc. Rev., 2017, 46, 3529-3614.

7 M. Chen, Q. Liu, S.-W. Wang, E. Wang, X. Guo and S.-L. Chou, Adv. Energy Mater., 2019, 9, 1803609.

8 M. Chen, E. Wang, Q. Liu, X. Guo, W. Chen, S.-L. Chou and S.-X. Dou, Energy Storage Mater., 2019, 19, 163-178.

9 L. Li, Y. Zheng, S. Zhang, J. Yang, Z. Shao and Z. Guo, Energy Environ. Sci., 2018, 11, 2310-2340.

10 Y. Li, Y. Lu, C. Zhao, Y.-S. Hu, M.-M. Titirici, H. Li, X. Huang and L. Chen, Energy Storage Mater., 2017, 7, 130-151.
11 Y. Cai, G. Fang, J. Zhou, S. Liu, Z. Luo, A. Pan, G. Cao and S. Liang, Nano Res., 2018, 11, 449-463.

12 Q. Zhang, Z. Wang, S. Zhang, T. Zhou, J. Mao and Z. Guo, Electrochem. Energy Rev., 2018, 1, 625-658.

13 Y.-H. Zhu, X. Yang, T. Sun, S. Wang, Y.-L. Zhao, J.-M. Yan and X.-B. Zhang, Electrochem. Energy Rev., 2018, 1, 548-566.

14 H. Kim, H. Ji, J. Wang and G. Ceder, Trends in Chemistry, 2019, 1, 682-692.

15 Y.-S. Xu, S.-Y. Duan, Y.-G. Sun, D.-S. Bin, X.-S. Tao, D. Zhang, Y. Liu, A.-M. Cao and L.-J. Wan, J. Mater. Chem. A, 2019, 7, 4334-4352.

16 T. Hosaka, T. Shimamura, K. Kubota and S. Komaba, Chem. Rec., 2019, 19, 735-745.

17 J. C. Pramudita, D. Sehrawat, D. Goonetilleke and N. Sharma, Adv. Energy Mater., 2017, 7, 1602911.

18 H. Kim, D. H. Seo, J. C. Kim, S. H. Bo, L. Liu, T. Shi and G. Ceder, Adv. Mater., 2017, 29, 1702480.

19 N. Naveen, W. B. Park, S. C. Han, S. P. Singh, Y. H. Jung, D. Ahn, K.-S. Sohn and M. Pyo, Chem. Mater., 2018, 30, 2049-2057.

20 Y.-H. Zhu, X. Yang, D. Bao, X.-F. Bie, T. Sun, S. Wang, Y.-S. Jiang, X.-B. Zhang, J.-M. Yan and Q. Jiang, Joule, 2018, 2, 736-746.

21 B. Wang, Y. Han, X. Wang, N. Bahlawane, H. Pan, M. Yan and Y. Jiang, iScience, 2018, 3, 110-133.

22 Z. Zhang, M. Li, Y. Gao, Z. Wei, M. Zhang, C. Wang, Y. Zeng, B. Zou, G. Chen and F. Du, Adv. Funct. Mater., 2018, 28, 1802684.

23 Z. Jian, Y. Liang, I. A. Rodríguez-Pérez, Y. Yao and X. Ji, Electrochem. Commun., 2016, 71, 5-8.

24 T. Masese, K. Yoshii, M. Kato, K. Kubota, Z. D. Huang, H. Senoh and M. Shikano, Chem. Commun., 2019, 55, 985-988.

25 H. Zhang, K. Xi, K. Jiang, X. Zhang, Z. Liu, S. Guo and H. Zhou, Chem. Commun., 2019, 55, 7910-7913.

26 X. Wu, D. P. Leonard and X. Ji, Chem. Mater., 2017, 29, 5031-5042.

27 X. Jiang, T. Zhang, L. Yang, G. Li and J. Y. Lee, ChemElectroChem, 2017, 4, 2237-2242.

28 X. Zou, P. Xiong, J. Zhao, J. Hu, Z. Liu and Y. Xu, Phys. Chem. Chem. Phys., 2017, 19, 26495-26506.

29 W. Zhang, Y. Liu and Z. Guo, Sci. Adv., 2019, 5, eaav7412.

30 C. Delmas, C. Fouassier and P. Hagenmuller, Physica $B+C$, 1980, 99, 81-85.

31 C. Vaalma, G. A. Giffin, D. Buchholz and S. Passerini, J. Electrochem. Soc., 2016, 163, A1295-A1299.

32 H. Kim, D.-H. Seo, A. Urban, J. Lee, D.-H. Kwon, S.-H. Bo, T. Shi, J. K. Papp, B. D. McCloskey and G. Ceder, Chem. Mater., 2018, 30, 6532-6539.

33 N. Yabuuchi, M. Kajiyama, J. Iwatate, H. Nishikawa, S. Hitomi, R. Okuyama, R. Usui, Y. Yamada and S. Komaba, Nat. Mater., 2012, 11, 512-517.

34 X. Wang, X. Xu, C. Niu, J. Meng, M. Huang, X. Liu, Z. Liu and L. Mai, Nano Lett., 2017, 17, 544-550.

35 K. Hurlbutt, S. Wheeler, I. Capone and M. Pasta, Joule, 2018, 2, 1950-1960. 
36 C. Zhang, Y. Xu, M. Zhou, L. Liang, H. Dong, M. Wu, Y. Yang and Y. Lei, Adv. Funct. Mater., 2017, 27, 1604307.

37 Z. Shadike, D.-R. Shi, T.-W. Tian-Wang, M.-H. Cao, S.-F. Yang, J. Chen and Z.-W. Fu, J. Mater. Chem. A, 2017, 5, 6393-6398.

38 S. Chong, Y. Chen, Y. Zheng, Q. Tan, C. Shu, Y. Liu and Z. Guo, J. Mater. Chem. A, 2017, 5, 22465-22471.

39 G. He and L. F. Nazar, ACS Energy Lett., 2017, 2, 1122-1127. 40 T. A. Y. Mizutani, K. Ikeda, E. Ihara, M. Asano, T. Harada, M. Inaba and Z. Ogumi, Carbon, 1997, 35, 61-65.

41 Z. Jian, W. Luo and X. Ji, J. Am. Chem. Soc., 2015, 137, 11566-11569.

42 C. Shen, K. Yuan, T. Tian, M. Bai, J. G. Wang, X. Li, K. Xie, Q. G. Fu and B. Wei, ACS Appl. Mater. Interfaces, 2019, 11, 5015-5021.

43 W. Luo, J. Wan, B. Ozdemir, W. Bao, Y. Chen, J. Dai, H. Lin, Y. Xu, F. Gu, V. Barone and L. Hu, Nano Lett., 2015, 15, 7671-7677.

44 J. Ding, H. Zhang, H. Zhou, J. Feng, X. Zheng, C. Zhong, E. Paek, W. Hu and D. Mitlin, Adv. Mater., 2019, 31, 1900429.

45 H. He, D. Huang, Y. Tang, Q. Wang, X. Ji, H. Wang and Z. Guo, Nano Energy, 2019, 57, 728-736.

46 K. Share, A. P. Cohn, R. Carter, B. Rogers and C. L. Pint, ACS Nano, 2016, 10, 9738-9744.

47 Y. Li, Y. Lu, P. Adelhelm, M. M. Titirici and Y. S. Hu, Chem. Soc. Rev., 2019, 48, 4655-4687.

48 W. Cao, E. Zhang, J. Wang, Z. Liu, J. Ge, X. Yu, H. Yang and B. Lu, Electrochim. Acta, 2019, 293, 364-370.

49 L. Zhang, S. Peng, Y. Ding, X. Guo, Y. Qian, H. Celio, G. He and G. Yu, Energy Environ. Sci., 2019, 12, 1989-1998.

50 W. Luo, Z. Jian, Z. Xing, W. Wang, C. Bommier, M. M. Lerner and X. Ji, ACS Cent. Sci., 2015, 1, 516-522.

51 Z. Luo, S. Liu, Y. Cai, S. Li, A. Pan and S. Liang, Sci. Bull., 2018, 63, 126-132.

52 D. Saurel, B. Orayech, B. Xiao, D. Carriazo, X. Li and T. Rojo, Adv. Energy Mater., 2018, 8, 1703268.

53 Z. Ju, S. Zhang, Z. Xing, Q. Zhuang, Y. Qiang and Y. Qian, ACS Appl. Mater. Interfaces, 2016, 8, 20682-20690.

54 R. A. Adams, J. M. Syu, Y. Zhao, C. T. Lo, A. Varma and V. G. Pol, ACS Appl. Mater. Interfaces, 2017, 9, 17872-17881.

55 G. Ma, K. Huang, J.-S. Ma, Z. Ju, Z. Xing and Q.-c. Zhuang, J. Mater. Chem. A, 2017, 5, 7854-7861.

56 J. Han, M. Xu, Y. Niu, G.-N. Li, M. Wang, Y. Zhang, M. Jia and C.-M. Li, Chem. Commun., 2016, 52, 11274-11276.

57 I. Sultana, M. M. Rahman, S. Mateti, V. G. Ahmadabadi, A. M. Glushenkov and Y. Chen, Nanoscale, 2017, 9, 36463654 .

58 X. Ren, Q. Zhao, W. D. McCulloch and Y. Wu, Nano Res., 2017, 10, 1313-1321.

59 R. Zhang, J. Bao, Y. Wang and C. F. Sun, Chem. Sci., 2018, 9, 6193-6198.

60 W. Zhang, J. Mao, S. Li, Z. Chen and Z. Guo, J. Am. Chem. Soc., 2017, 139, 3316-3319.

61 K. Lei, C. Wang, L. Liu, Y. Luo, C. Mu, F. Li and J. Chen, Angew. Chem., Int. Ed., 2018, 57, 4687-4691.
62 K. Huang, Z. Xing, L. Wang, X. Wu, W. Zhao, X. Qi, H. Wang and Z. Ju, J. Mater. Chem. A, 2018, 6, 434-442.

63 Z. Chen, D. Yin and M. Zhang, Small, 2018, 14, 1703818.

64 Q. Zhang, J. Mao, W. K. Pang, T. Zheng, V. Sencadas, Y. Chen, Y. Liu and Z. Guo, Adv. Energy Mater., 2018, 8, 1703288.

65 M. Chen, D. Cortie, Z. Hu, H. Jin, S. Wang, Q. Gu, W. Hua, E. Wang, W. Lai, L. Chen, S.-L. Chou, X.-L. Wang and S.-X. Dou, Adv. Energy Mater., 2018, 8, 1800944.

66 M. Chen, L. Chen, Z. Hu, Q. Liu, B. Zhang, Y. Hu, Q. Gu, J.-L. Wang, L.-Z. Wang, X. Guo, S.-L. Chou and S.-X. Dou, Adv. Mater., 2017, 29, 1605535.

67 M. Chen, W. Hua, J. Xiao, D. Cortie, W. Chen, E. Wang, Z. $\mathrm{Hu}, \mathrm{Q}$. Gu, X. Wang, S. Indris, S. L. Chou and S. X. Dou, Nat. Commun., 2019, 10, 1480.

68 G. Yan, S. Mariyappan, G. Rousse, Q. Jacquet, M. Deschamps, R. David, B. Mirvaux, J. W. Freeland and J. M. Tarascon, Nat. Commun., 2019, 10, 585.

69 V. Mathew, S. Kim, J. Kang, J. Gim, J. Song, J. P. Baboo, W. Park, D. Ahn, J. Han, L. Gu, Y. Wang, Y.-S. Hu, Y.-K. Sun and J. Kim, NPG Asia Mater., 2014, 6, e138.

70 E. Wang, W. Xiang, R. Rajagopalan, Z. Wu, J. Yang, M. Chen, B. Zhong, S. X. Dou, S. Chou, X. Guo and Y.-M. Kang, J. Mater. Chem. A, 2017, 5, 9833-9841.

71 E. Wang, M. Chen, X. Liu, Y. Liu, H. Guo, Z. Wu, W. Xiang, B. Zhong, X. Guo, S. Chou and S.-X. Dou, Small Methods, 2019, 3, 1800169.

72 J. Han, G. N. Li, F. Liu, M. Wang, Y. Zhang, L. Hu, C. Dai and M. Xu, Chem. Commun., 2017, 53, 1805-1808.

73 X. Wang, C. Niu, J. Meng, P. Hu, X. Xu, X. Wei, L. Zhou, K. Zhao, W. Luo, M. Yan and L. Mai, Adv. Energy Mater., 2015, 5, 1500716.

74 L. Zhang, B. Zhang, C. Wang, Y. Dou, Q. Zhang, Y. Liu, H. Gao, M. Al-Mamun, W. K. Pang, Z. Guo, S. X. Dou and H. K. Liu, Nano Energy, 2019, 60, 432-439.

75 J. Han, Y. Niu, S. J. Bao, Y. N. Yu, S. Y. Lu and M. Xu, Chem. Commun., 2016, 52, 11661-11664.

76 L. Peng, Y. Zhu, X. Peng, Z. Fang, W. Chu, Y. Wang, Y. Xie, Y. Li, J. J. Cha and G. Yu, Nano Lett., 2017, 17, 6273-6279.

77 J. Hyoung, J. W. Heo, M. S. Chae and S. T. Hong, ChemSusChem, 2019, 12, 1069-1075.

78 K. Chihara, A. Katogi, K. Kubota and S. Komaba, Chem. Commun., 2017, 53, 5208-5211.

79 R. Lian, D. Wang, X. Ming, R. Zhang, Y. Wei, J. Feng, X. Meng and G. Chen, J. Mater. Chem. A, 2018, 6, 1622816234.

80 J. Ding, Y.-C. Lin, J. Liu, J. Rana, H. Zhang, H. Zhou, I.-H. Chu, K. M. Wiaderek, F. Omenya, N. A. Chernova, K. W. Chapman, L. F. J. Piper, S. P. Ong and M. S. Whittingham, Adv. Energy Mater., 2018, 8, 1800221.

81 J. Liao, Q. Hu, B. Che, X. Ding, F. Chen and C. Chen, J. Mater. Chem. A, 2019, 7, 15244-15251.

82 J. Liao, Q. Hu, J. Mu, X. He, S. Wang and C. Chen, Chem. Commun., 2019, 55, 659-662.

83 K.-H. Ha, S. H. Woo, D. Mok, N.-S. Choi, Y. Park, S. M. Oh, Y. Kim, J. Kim, J. Lee, L. F. Nazar and K. T. Lee, Adv. Energy Mater., 2013, 3, 770-776. 
84 V. M. Kovrugin, J.-N. Chotard, F. Fauth, A. Jamali, R. David and C. Masquelier, J. Mater. Chem. A, 2017, 5, 14365-14376.

85 P. Barpanda, G. Liu, C. D. Ling, M. Tamaru, M. Avdeev, S.-C. Chung, Y. Yamada and A. Yamada, Chem. Mater., 2013, 25, 3480-3487.

86 W. B. Park, S. C. Han, C. Park, S. U. Hong, U. Han, S. P. Singh, Y. H. Jung, D. Ahn, K.-S. Sohn and M. Pyo, Adv. Energy Mater., 2018, 8, 1703099.

87 N. Recham, G. Rousse, M. T. Sougrati, J.-N. Chotard, C. Frayret, S. Mariyappan, B. C. Melot, J.-C. Jumas and J.-M. Tarascon, Chem. Mater., 2012, 24, 4363-4370.

88 P. Serras, V. Palomares, J. Alonso, N. Sharma, J. M. López del Amo, P. Kubiak, M. L. Fdez-Gubieda and T. Rojo, Chem. Mater., 2013, 25, 4917-4925.

89 J. S. Ko, V. V. T. Doan-Nguyen, H.-S. Kim, X. Petrissans, R. H. DeBlock, C. S. Choi, J. W. Long and B. S. Dunn, J. Mater. Chem., 2017, 5, 18707-18715.

90 Q. Li, Z. Liu, F. Zheng, R. Liu, J. Lee, G. L. Xu, G. Zhong, X. Hou, R. Fu, Z. Chen, K. Amine, J. Mi, S. Wu, C. P. Grey and Y. Yang, Angew. Chem., Int. Ed., 2018, 57, 11918-11923.

91 H. Kim, D.-H. Seo, M. Bianchini, R. J. Clément, H. Kim, J. C. Kim, Y. Tian, T. Shi, W.-S. Yoon and G. Ceder, Adv. Energy Mater., 2018, 8, 1801591.

92 S. S. Fedotov, A. S. Samarin, V. A. Nikitina, D. A. Aksyonov, S. A. Sokolov, A. Zhugayevych, K. J. Stevenson, N. R. Khasanova, A. M. Abakumov and E. V. Antipov, J. Mater. Chem. A, 2018, 6, 14420-14430.

93 X. Lin, J. Huang, H. Tan, J. Huang and B. Zhang, Energy Storage Mater., 2019, 16, 97-101.

94 S.-P. Guo, J.-C. Li, Q.-T. Xu, Z. Ma and H.-G. Xue, J. Power Sources, 2017, 361, 285-299.

95 R. Tripathi, G. R. Gardiner, M. S. Islam and L. F. Nazar, Chem. Mater., 2011, 23, 2278-2284.

96 B. C. Melot, G. Rousse, J. N. Chotard, M. C. Kemei, J. Rodríguez-Carvajal and J. M. Tarascon, Phys. Rev. B: Condens. Matter Mater. Phys., 2012, 85, 094415.

97 L. Lander, G. Rousse, A. M. Abakumov, M. Sougrati, G. van Tendeloo and J.-M. Tarascon, J. Mater. Chem. A, 2015, 3, 19754-19764.

98 D. Cui, D. Tian, S. Chen and L. Yuan, J. Mater. Chem. A, 2016, 4, 9177-9183.

99 H. Banda, D. Damien, K. Nagarajan, M. Hariharan and M. M. Shaijumon, J. Mater. Chem. A, 2015, 3, 10453-10458. 100 S. Wang, L. Wang, Z. Zhu, Z. Hu, Q. Zhao and J. Chen, Angew. Chem., Int. Ed., 2014, 53, 5892-5896.

101 W. Luo, M. Allen, V. Raju and X. Ji, Adv. Energy Mater., 2014, 4, 1400554.

102 Y. Chen, W. Luo, M. Carter, L. Zhou, J. Dai, K. Fu, S. Lacey, T. Li, J. Wan, X. Han, Y. Bao and L. Hu, Nano Energy, 2015, 18, 205-211.

103 Z. Xing, Z. Jian, W. Luo, Y. Qi, C. Bommier, E. S. Chong, Z. Li, L. Hu and X. Ji, Energy Storage Mater., 2016, 2, 63-68.

104 L. Fan, R. Ma, J. Wang, H. Yang and B. Lu, Adv. Mater., 2018, 30, 1805486.

105 H. Gao, L. Xue, S. Xin and J. B. Goodenough, Angew. Chem., Int. Ed., 2018, 57, 5449-5453.
106 A. Slesarenko, I. K. Yakuschenko, V. Ramezankhani, V. Sivasankaran, O. Romanyuk, A. V. Mumyatov, I. Zhidkov, S. Tsarev, E. Z. Kurmaev, A. F. Shestakov, O. V. Yarmolenko, K. J. Stevenson and P. A. Troshin, J. Power Sources, 2019, 435, 226724.

107 M. Tang, Y. Wu, Y. Chen, C. Jiang, S. Zhu, S. Zhuo and C. Wang, J. Mater. Chem. A, 2019, 7, 486-492.

108 B. Tian, J. Zheng, C. Zhao, C. Liu, C. Su, W. Tang, X. Li and G.-H. Ning, J. Mater. Chem. A, 2019, 7, 9997-10003.

109 Q. Xue, D. Li, Y. Huang, X. Zhang, Y. Ye, E. Fan, L. Li, F. Wu and R. Chen, J. Mater. Chem. A, 2018, 6, 12559-12564.

110 C. Zhang, Y. Qiao, P. Xiong, W. Ma, P. Bai, X. Wang, Q. Li, J. Zhao, Y. Xu, Y. Chen, J. H. Zeng, F. Wang, Y. Xu and J. X. Jiang, ACS Nano, 2019, 13, 745-754.

111 Y. Zhu, P. Chen, Y. Zhou, W. Nie and Y. Xu, Electrochim. Acta, 2019, 318, 262-271.

112 S.-Y. Yang, Y.-J. Chen, G. Zhou and Z.-W. Fu, J. Electrochem. Soc., 2018, 165, A1422-A1429.

113 C. Wang, W. Tang, Z. Yao, Y. Chen, J. Pei and C. Fan, Org. Electron., 2018, 62, 536-541.

114 B. Li, J. Zhao, Z. Zhang, C. Zhao, P. Sun, P. Bai, J. Yang, Z. Zhou and Y. Xu, Adv. Funct. Mater., 2019, 29, 1807137.

115 W. Lee, A. Permatasari, B. W. Kwon and Y. Kwon, Chem. Eng. J., 2019, 358, 1438-1445.

116 H. Fei, Y. Liu, Y. An, X. Xu, G. Zeng, Y. Tian, L. Ci, B. Xi, S. Xiong and J. Feng, J. Power Sources, 2018, 399, 294-298.

117 X. Chen, H. Zhang, C. Ci, W. Sun and Y. Wang, ACS Nano, 2019, 13, 3600-3607.

118 Q. Zhao, J. Wang, Y. Lu, Y. Li, G. Liang and J. Chen, Angew. Chem., Int. Ed., 2016, 55, 12528-12532.

119 J. Zhao, J. Yang, P. Sun and Y. Xu, Electrochem. Commun., 2018, 86, 34-37.

120 C. Wang, W. Tang, Z. Yao, B. Cao and C. Fan, Chem. Commun., 2019, 55, 1801-1804.

121 Y. Liang, C. Luo, F. Wang, S. Hou, S.-C. Liou, T. Qing, Q. Li, J. Zheng, C. Cui and C. Wang, Adv. Energy Mater., 2019, 9, 1802986.

122 C. Li, J. Xue, J. Ma and J. Li, J. Electrochem. Soc., 2018, 166, A5221-A5225.

123 C. Fan, M. Zhao, C. Li, C. Wang, B. Cao, X. Chen, Y. Li and J. Li, Electrochim. Acta, 2017, 253, 333-338.

124 L. Chen and Y. Zhao, Mater. Lett., 2019, 243, 69-72.

125 Y. Tang, J. Deng, W. Li, O. I. Malyi, Y. Zhang, X. Zhou, S. Pan, J. Wei, Y. Cai, Z. Chen and X. Chen, Adv. Mater., 2017, 29, 1701828.

126 Y. Tang, Y. Zhang, O. I. Malyi, N. Bucher, H. Xia, S. Xi, Z. Zhu, Z. Lv, W. Li, J. Wei, M. Srinivasan, A. Borgna, M. Antonietti, Y. Du and X. Chen, Adv. Mater., 2018, 30, 1802200.

127 Z. Zhu, Y. Tang, W. R. Leow, H. Xia, Z. Lv, J. Wei, X. Ge, S. Cao, Y. Zhang, W. Zhang, H. Zhang, S. Xi, Y. Du and X. Chen, Angew. Chem., Int. Ed., 2019, 58, 3521-3526.

128 Y. Zhang, Y. Tang, J. Deng, W. R. Leow, H. Xia, Z. Zhu, Z. Lv, J. Wei, W. Li, C. Persson, O. I. Malyi, M. Antonietti and X. Chen, ACS Mater. Lett., 2019, 1, 519-525.

129 L. Fan, R. Ma, Q. Zhang, X. Jia and B. Lu, Angew. Chem., Int. Ed., 2019, 58, 10500-10505. 
130 W. Zhang, X. Sun, Y. Tang, H. Xia, Y. Zeng, L. Qiao, Z. Zhu, Z. Lv, Y. Zhang, X. Ge, S. Xi, Z. Wang, Y. Du and X. Chen, J. Am. Chem. Soc., 2019, 141, 14038-14042.

131 J. Liu, T. Yin, B. Tian, B. Zhang, C. Qian, Z. Wang, L. Zhang, P. Liang, Z. Chen, J. Yan, X. Fan, J. Lin, X. Chen, Y. Huang, K. P. Loh and Z. X. Shen, Adv. Energy Mater., 2019, 9, 1900579.

132 J. W. Nai and X. W. Lou, Adv. Mater., 2019, 31, 1706825.
133 Y. Tang, Y. Zhang, X. Rui, D. Qi, Y. Luo, W. R. Leow, S. Chen, J. Guo, J. Wei, W. Li, J. Deng, Y. Lai, B. Ma and X. Chen, Adv. Mater., 2016, 28, 1567-1576.

134 J. Wang, L. Fan, Z. Liu, S. Chen, Q. Zhang, L. Wang, H. Yang, X. Yu and B. Lu, ACS Nano, 2019, 13, 3703-3713. 135 Y. Feng, S. Chen, J. Wang and B. Lu, J. Energy Chem., 2020, 43, 129-138. 